Portland State University

PDXScholar

\title{
A study of the narrative skills in kindergarten children with normal, impaired, and late developing language development
}

Lisa L. McFarland

Portland State University

Follow this and additional works at: https://pdxscholar.library.pdx.edu/open_access_etds

Part of the Speech and Hearing Science Commons

Let us know how access to this document benefits you.

\section{Recommended Citation}

McFarland, Lisa L., "A study of the narrative skills in kindergarten children with normal, impaired, and late developing language development" (1992). Dissertations and Theses. Paper 4417.

https://doi.org/10.15760/etd.6294

This Thesis is brought to you for free and open access. It has been accepted for inclusion in Dissertations and Theses by an authorized administrator of PDXScholar. Please contact us if we can make this document more accessible: pdxscholar@pdx.edu. 
AN ABSTRACT OF THE THESIS OF Lisa L. McFarland for the Master of Science in Speech Communication: Speech and Hearing science presented June 2, 1992.

Title: A study of the Narrative Skills in Kindergarten Children with Normal, Impaired, and Late Developing Language Development.

APPROVED BY MEMBERS OF THE THESIS COMMITTEE:

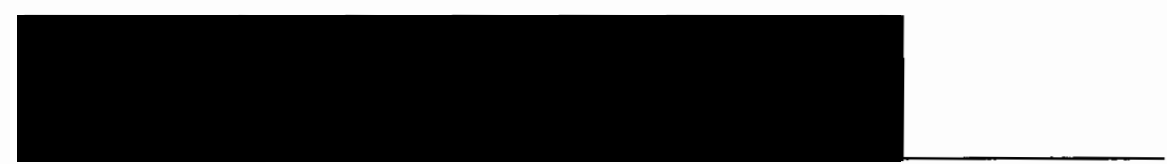

Rhea Paul, Chairperson

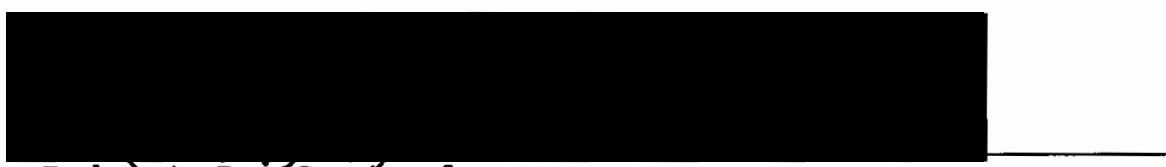

Robert L. Casteel

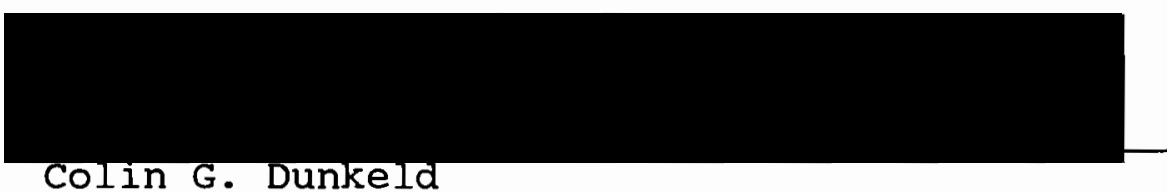

Children's narrative language plays a critical role in guiding the transition between oral language and literacy (Roth \& Spekman, 1989; Westby, 1989). Narrative comprehension and production by normally achieving and language delayed school-aged children have been studied. Many of these studies have involved story retellings. Few have studied how spontaneously produced narratives are organized especially by young children. 
The purpose of this study was to compare the narrative ability (using a wordless picture book) of kindergarten children with differing rates of language development. Subjects were assigned to three diagnostic groups (normal, history of expressive language delay, or expressive language delayed) on the basis of their original diagnoses at age 20-34 months (normal or late talker) and their Developmental Sentence Scoring (Lee, 1974) at kindergarten age.

At kindergarten age, each child was audiotaped producing a spontaneous narrative, using a wordless picture book. The narratives were scored on 6 measures: Mean Length of Utterance per T-unit, Type-Token Ratio, Lexical Richness, Cohesion, Information, and Narrative Stage Assignment.

Results of ANOVA and Tukey multiple comparison procedures indicated significant differences between the normal language group and the expressive language delayed (ELD) group on the measures of lexical richness--the number of unusual word types, cohesion--the percentage of complete ties used, and narrative stage assignment. No significant differences were found between the history of expressive language delay ( $\mathrm{Hx}$ ) and the normal language groups, except on the measure of lexical richness--the number of unusual word types. No significant differences were found between the $\mathrm{HX}$ and the ELD groups. 


\title{
A STUDY OF THE
}

NARRATIVE SKILLS IN KINDERGARTEN CHILDREN WITH

NORMAL, IMPAIRED, AND LATE DEVELOPING LANGUAGE DEVELOPMENT

by

LISA L. MCFARLAND

A thesis submitted in partial fulfillment of the requirements for the degree of

\author{
MASTER OF SCIENCE \\ in \\ SPEECH COMMUNICATION : \\ SPEECH AND HEARING SCIENCE
}

Portland State University

1992 
TO THE OFFICE OF GRADUATE STUDIES:

The members of the Committee approve the thesis of Lisa L. McFarland presented June 2, 1992.

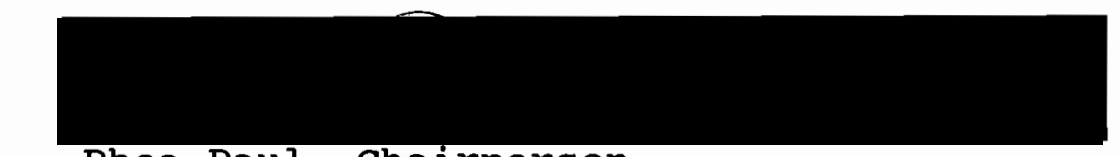

Rhea Paul, Chairperson

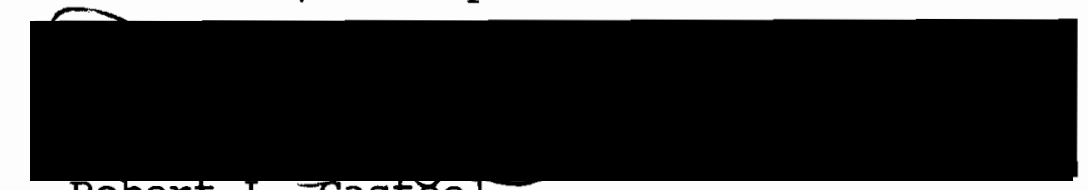

Robert L."Castēel

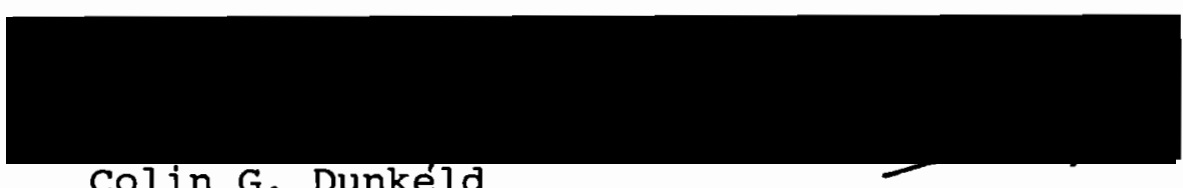

Colin G. Dunkéld

\section{APPROVED :}

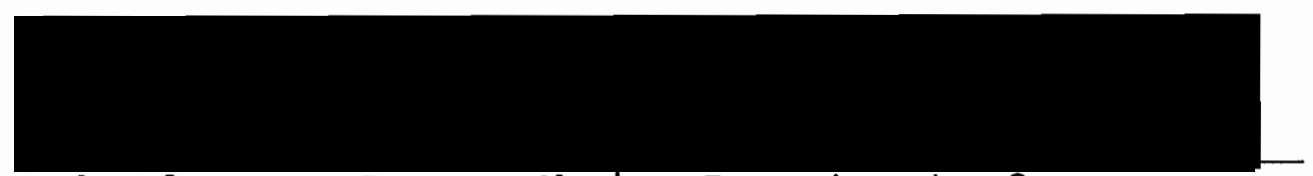

Theodore G. Grove, Chair, Department of Speech Communication

C. William Savery, Vice Provoft for Graduate Studies and Research 


\section{ACKNOWLEDGEMENTS}

I wish to thank Dr. Rhea Paul for her continual support and encouragement. I am grateful for the opportunity to have been her graduate research assistant for these past two years.

I extend my gratitude to Dr. Robert Casteel, my academic advisor and Thesis committee member, for his constant assurance, and to Dr. Colin Dunkeld, for his contributions.

My appreciation goes to the parents and children involved in the Portland Language Development Project.

I am especially grateful to fellow research assistants Rita Smith, Randi Jartun, and Karen Johnson, with whom I shared many memorable moments. I thank them for their assistance and encouragement.

Finally, my deepest thanks to my husband Bill McFarland and my mother and sister, my most valuable sources of support. 
TABLE OF CONTENTS

PAGE

ACKNOWLEDGEMENTS . . . . . . . . . . . . . . . ii

LIST OF TABLES . . . . . . . . . . . . . . . . vii

CHAPTER

I INTRODUCTION . . . . . . . . . . . . . . 1

Statement of Purpose. . . . . . . . 2

Definition of Terms . . . . . . . 3

II REVIEW OF THE LITERATURE . • . • • • • • 7

Narrative Development . . . . . . 7

Story Grammar

Narrative Stage

Cohesion

Information

Lexical Diversity

Forms of Narration

Narrative SKills in Children with

Language Difficulties. . . . . 12

Narrative Stage

Cohesion

Information

Lexical Diversity

Previous Study of Subjects

in this study

Summary

Background to Current study . . . . 18

III METHODS AND PROCEDURES . . . . . . . . . 21

Subjects. . . . . . . . . . . . 21

Subject Description at Intake:

Age 2 
PAGE

Follow-up Assessment: Kindergarten

Criteria for Language Diagnostic

Group Assignment: Kindergarten

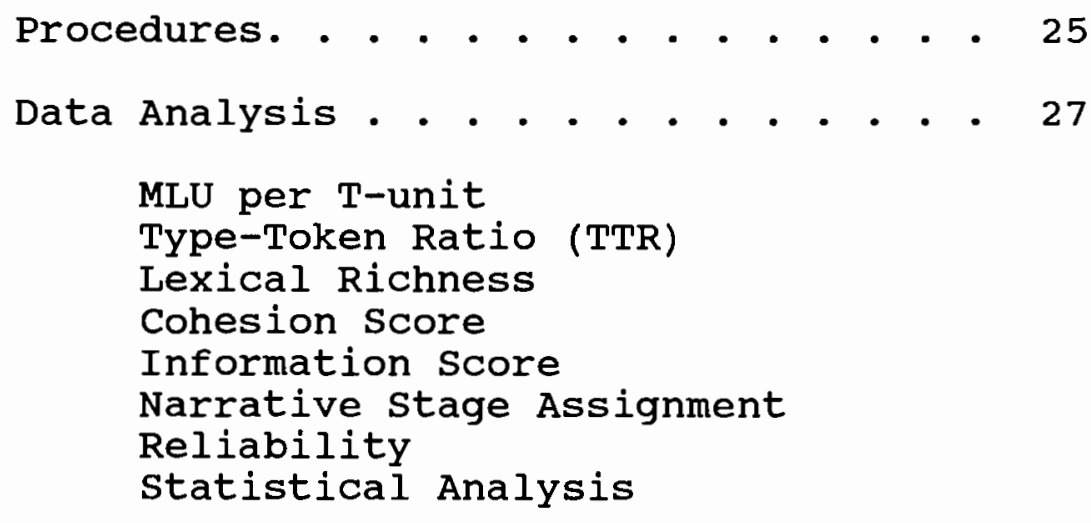

IV RESULTS AND DISCUSSION . . . . . . . . 38

Results . . . . . . . . . . 38

Lexical Richness: number of unusual word types

Cohesion: percentage of complete ties

Narrative stage assignment

Discussion. . . . . . . . . . 43

V SUMMARY AND IMPLICATIONS . . . . . . . 47

Summary . . . . . . . . . . . 47

Implications. . . . . . . . . . 49

Research

clinical

REFERENCES

APPENDICES

A DEVELOPMENTAL SENTENCE SCORE:

SCORING CRITERIA. . . . . . . . . . . 56

B DEVELOPMENTAL SENTENCE SCORE:

NORMS • . • • • • • • • • • • • • 59 
PAGE

C OREGONIAN ARTICLE . . . . . . . . . . . 61

D HUMAN SUBJECTS RESEARCH FORMS (D1 \& D2) • • . 63

E PARENT PERMISSION FORM. . . . . . . . . 66

F QUESTIONNAIRE FOR PARENTS OF CHILDREN 15-30 MONTHS OLD. . . . . . . . . . . 68

G LANGUAGE DEVELOPMENTAL SURVEY . . . . . . 70

H RULES FOR COUNTING T-UNITS AND WORDS. • . . 73

I 500 MOST COMMON WORDS USED BY 6 YEAR OLDS • . 75

J COHESION SCORING PROCEDURE. • • • • • • • 79

K INFORMATION SCORE CRITERIA. . . . . . . 85 


\section{LIST OF TABLES}

TABLE

PAGE

I Group Demographic Information at Intake and Follow-up . . . . 23

II Group Description at Kindergarten. . . 26

III Range, Mean, and Standard Deviation of Each Group for Each of the Dependent Measures. . . . . . 39

IV ANOVA, Tukey Test, and Kruskal-Wallis Test Results. . . . . . . . . 41 


\section{CHAPTER I}

\section{INTRODUCTION}

According to Halliday and Hasan (1976, p.1), a text is "any passage, spoken or written, of whatever length, that does form a unified whole." A narrative is a text that is an account of events from a human perspective, relating the events over time (Peterson \& McCabe, 1983). Researchers are finding that children's narrative language plays a critical role in guiding the transition between oral language and literacy (Roth \& Spekman, 1989; Westby, 1989). Since research indicates that narrative ability is important for reading comprehension and school success (Roth \& Spekman, in Kamhi \& Catts, 1989), children with problems comprehending or producing narratives may be at risk for language and/or learning problems in the school setting. In fact, Feagans \& Applebaum (1986) indicate that narrative proficiency may be the most effective single linguistic predictor of resolution of language impairment in preschool children with language disorders. Narrative skill and reading ability rely on higher level language skills (Roth \& Spekman, in Kamhi \& Catts, 1986); therefore, children with language disorders may be at risk for reading and later learning problems. Donahue (1986) suggests that not only will those preschool children 
identified early with oral language disorders have problems, but those children not identified until school-age who may have more subtle language problems, may have reading deficits as well.

Narrative comprehension and production by normally achieving and language delayed school-aged children have been studied. Although many of these studies have been done involving children retelling stories, few have studied how spontaneously produced narratives are organized especially by young children.

\section{STATEMENT OF PURPOSE}

The purpose of this study was to compare the spontaneous narrative abilities of 3 groups of kindergarten children with different language diagnoses. The three groups identified were kindergarten children with normal, impaired, and late developing oral language. The subjects were assigned to these three groups on the basis of their original diagnoses at age two (normal or late talker) and their Developmental sentence Score at kindergarten. Because of their delays in the acquisition of oral skills, the subjects with impaired and late developing oral language were expected to not perform as well as their peers with normal language development on a narrative task which relies on higher level language skills. The question addressed in this study was:

will kindergarten children with differing rates of 
language development produce spontaneous narratives that differ significantly from each other's on 6 different measures of narrative skill?

The research hypothesis for this study is as follows: Kindergarten children with impaired and late developing language will score significantly lower than children with normal language on the 6 different measures of spontaneous narrative skill.

The null hypothesis is:

Given the spontaneous narrative samples of 3 groups of kindergarten children with differing rates of language development, there will be no significant differences among scores on 6 different measures of narrative skill.

\section{DEFINITION OF TERMS}

Cohesion: Cohesion is a semantic system of ties across sentences that binds a text together (Nelson, in Nippold, 1988). Liles (1985) defines a cohesive marker as an element whose meaning cannot be interpreted without searching outside the sentence for the completed meaning. She identifies 3 cohesive categories: 1) reference-the information to be retrieved is the identity of the thing or class of things being referred to in the preceding or following text, 2) conjunction-specification of the way content that has gone before is to tie together with the content to follow, and 3) lexical-vocabulary which cues the listener that the 
information is recoverable outside the sentence. Cohesive markers are judged to be complete ties if the information referred to by the cohesive marker is easily found, to be noncomplete if the information is not provided in the text or if the listener is guided to ambiguous information.

Developmental Sentence Score (DSS) (Lee, 1974): A method of quantification of syntactic complexity of children's language. Utterances from spontaneous language samples containing a subject-predicate relationship are scored for constituents of eight grammatical categories according to Lee's (1974) criteria (Appendix A). Lee has established norms for the DSS (Appendix B).

Expressive Language Delayed (ELD) Subjects: The subjects were considered to be ELD if they were late talkers at age 20-34 months, using the Language Developmental survey (LDS) (Rescorla, 1989) criterion, and also received a score below 6.35 (10th percentile for age 5.0) on the DSS (Lee, 1974) at kindergarten age.

History of Expressive Lanquage Delay (Hx) Subjects: The subjects were considered to be $\mathrm{Hx}$ if they were identified as late talkers at age 20-34 months, using the LDS, but who at kindergarten age scored 6.35 or above (10th percentile for age 5.0) on the DSS (Lee, 1974). 
Information score: The information score is the total number of relevant propositions, or ideas, the subject included in the narrative, out of a total of 26 essential propositions determined by the investigator.

Late Talkers: The subjects were considered to be late talkers if they used less than 50 different words at age 20-34 months as reported by the parents on the LDS (Rescorla, 1989).

Lexical Richness: The number of unusual words types used by the child in his/her narrative. Unusual words are defined as words that were not on Wepman and Hass' list of the 500 most common words used by 6 year olds.

Narrative stage: The narrative stage assignment reflects the subject's level of narrative development as outlined by Applebee (1978). According to Applebee (1978), heap stories are defined as the least complex stage, followed by sequences, primitive narratives, chains, and finally true narratives being the most complex stage of narrative development. Each subject's narrative will be given a score from 1 to 5 , reflecting the stage assignment. A heap story receives a score of 1 and consists of simple labeling or description of activities. A sequence story receives a score of 2 and consists only of a description of a character's activities. A primitive narrative receives a score of 3 and consists of some cause-effect or temporal relationships among events, yet lacks an overall logical action plan and psychological 
motivations of characters. A chain receives a score of 4 and consists of some character motivation, some cause-effect and temporal linking, and a sense of plot through logical sequencing of action, yet lacks basic story grammar parts such as internal response, plan, and resolution. A true narrative receives a score of 5 and consists of elaborate character development and includes all the basic story grammar parts, especially shifts in character's psychological states and story resolution.

Normal Subjects: The subjects were considered to be normal if they used more than 50 different words at age 20-34 months as reported by the parents on the LDS and also scored 6.35 or above (10th percentile for age 5.0) on the DSS (Lee, 1974) at kindergarten age.

T-unit: A T-unit is a terminal unit of language, consisting of a main clause with all subordinate clauses or nonclausal structures attached to or embedded within. All main clauses that begin with coordinating conjunctions AND, BUT, OR initiate a new T-unit unless there is co-referential subject deletion in the second clause (Scott, in Nippold, 1988).

Type-Token Ratio (TTR): The type-token ratio is an index of lexical diversity calculated by dividing the total number of words used (tokens) into the total number of different words (types) used (Miller, 1981). 
CHAPTER II

\section{REVIEW OF THE LITERATURE}

During the school years, academic knowledge is exchanged primarily through the means of discourse (Roth, 1986). Schooling demands the increased ability to process and produce larger units of language (Garnett, 1986). Narration is a form of discourse that requires the speaker to carry on a monologue and to produce extended units of text containing an introduction and an organized sequence of events which lead to a logical conclusion (Roth, 1986). Narration involves "creating themes, characters, and symbols, devising plots, and producing coherent and causal sequences" (Kemper \& Edwards, 1986, p. 18). Narratives are ever-present in the language of the home and school. Understanding normal narrative development is crucial for predicting what deficits place a child at risk for academic failure.

\section{NARRATIVE DEVELOPMENT}

\section{Story Grammar}

Narratives can be described with a set of rules that define their structure, rules that dictate the parts of the story and the relations among the parts. This mental representation is called story grammar (Page \& Stewart, 1985). 
According to stein and Glenn (1979), a story grammar is made up of a setting plus an episode structure. An episode is made up of an initiating event + an internal response + a plan + an attempt + a consequence + a reaction. The categories are related or linked to each other either additively (i.e., and), temporally (i.e., then), or causally (i.e., because) (Garnett, 1985). Story grammars are used for comprehending, recalling, and producing stories. Growth in structural complexity and use of story grammar is developmental (Page \& stewart, 1985). Stein and Glenn (1979) showed that by 11-12 years of age, normal children produced full story grammars and connected the sentences within and across episodes (Roth \& Spekman, 1986). Beyond age six, children's narratives include more of story grammar categories, especially characters' inner responses and the relations to their plans and actions (Garnett, 1985; Sutton-Smith, 1986).

\section{Narrative Stage}

Although narratives with some degree of story grammar are produced by 6 year olds, preschoolers develop toward story grammar organization in predictable stages. Applebee (1978) has proposed an outline of the development of children's narratives during the preschool period:

1. Heap stories $(2-21 / 2$ years): According to Applebee (1978), there is no apparent organization among propositions. Organization comes from whatever attracts the child's attention. Stories consist of labeling or describing 
activities. Sentences are usually simple declaratives in present progressive tense (Westby, 1984).

2. Sequences (2 1/2 - 3 years): According to Applebee (1978), a sequence is a story of associations between a central setting or character and activities. The associations are based on similarities, rather than causality or temporal sequence.

3. Primitive Narratives ( 3 years): According to Applebee (1978), these stories are organized around a central character or object. It is a description of characteristics or events that are associated with the central core.

4. Unfocused Chain (3 years): This structure consists of a series of incidents that lead directly from one to another, but the attributes which link them continue to shift-characters pass in and out, action changes, and settings blur (Applebee, 1978). Children now perceive logical, temporal, or cause-effect relationships among events (Westby, 1984).

5. Focused Chain (4-5 years): According to Applebee (1978), this structure has a central core around which a series of situations is organized. The main character goes through a series of actions and events that are linked to one another.

6. True Narrative (6 years): According to Applebee (1978), a true narrative extends the focused chain by including the motivations behind the characters' actions (Westby, 1984) 


\section{Cohesion}

Halliday and Hasan (1976) described in detail cohesion in English and identified five kinds of cohesion processes: lexical cohesion, which involves semantic linking among vocabulary; grammatical cohesion which includes reference, substitution, and ellipsis; and conjunction strategies (additive, temporal, adversative, and causal) which link ideas (Nelson, cited in Nippold, 1988). As children grow older, they increasingly use and understand a greater number and variety of cohesive linking, expressing more and more complex relations in their narratives (Garnett, 1985). Children proceed from scanty, additive and temporally linked structures to complete, often embedded episodes, usually linked causally (Garnett, 1985).

\section{Information}

oral discourse requires that essential information is adequately conveyed. Informativeness refers to the ability to make appropriate inferences about what information is shared and what needs to be explicitly stated. With age, children present information more precisely and efficiently (Roth \& Spekman, cited in Kamhi \& Catts, 1989).

\section{Lexical Diversity}

Narrative maturity may also be measured in terms of vocabulary use. According to Finn (1977), the following represent mature word choices: low frequency words, abstract 
nouns, cognitive verbs, and adjectives that reveal a judgment (Nelson, cited in Nippold, 1988). The use of computer data bases to compare word choices and the Type-Token Ratio are both means of quantifying the diversity of children's vocabulary in a narrative sample.

\section{Forms of Narration}

Oral narration includes retelling stories and selfgenerated storytelling. Feagans and Applebaum's (1986, cited in Roth \& Spekman, 1989) longitudinal data indicates that proficiency in oral narration is the most effective single linguistic predictor of reading comprehension achievement in elementary school-aged children. Research shows that recalling the components of a story, temporally sequencing the events, and linking the events to each other and to the whole are necessary for successful narration, or retelling of a story. A story retelling task can be done in several ways. An examiner can tell a story while showing pictures and then ask the child to retell the story, or the examiner can show a movie and then ask the child to retell the story. In both of these cases, the ideas and the organization are provided for the child who is only required to linguistically encode the ideas into a meaningful whole.

Few researchers have studied self-generated narratives produced by school-aged children, especially young schoolagers. Constructing an original story is much more complex than retelling a story. Story generation involves formulating 
ideas, planning and organizing them (via story grammar), and connecting them linguistically (Roth \& Spekman, 1986). Producing stories about poster pictures or making up a story about anything requires children to have content schema knowledge of the physical and social world and in addition to have text grammar knowledge for the structure of narratives.

NARRATIVE SKILLS IN CHILDREN WITH LANGUAGE DIFFICULTIES

Narrative development in children with language difficulties has been widely studied. The topics of research have also varied in terms of the different aspects of narrative skill studied. Narrative ability is not determined by just one skill, rather a number of skills are necessary for producing a comprehensive narrative. The following discussion examines the narrative skills of children with language difficulties.

\section{Narrative Stage}

with regard to story structure and complexity, Westby, Maggart, and Van Dongen (1984) found that the low and clinic reading groups (third, fourth, and fifth graders) produced stories (from a poster picture) that were significantly less complex with fewer elements of meaning in each narrative clause than those of the average grade readers (Roth, 1986). Furthermore, Fry, Johnson, and Muehl (1970) and Smiley, Worthen, Campione, and Brown (1977) found that in retellings, poor readers used less complex linguistic patterns. Roth and 
Spekman (1986) found that on fictional stories, learning disabled children told stories containing a significantly smaller proportion of complete episodes and tended to omit the middle parts of the story. McNamee and Harris-Schmidt (1985) found that stories retold by learning disabled children between 5-9 years of age received lower rankings on the Applebee scale, indicating less complex linking of actions and ideas (Roth \& Spekman, 1986).

In general, children with language learning difficulties have trouble producing structurally complex narratives and forming complete episodes.

One study in particular investigated story generation and story retelling abilities of the same 3 groups of children: dyslexic children, children with reading retardation, and normal children (mean age was 9 years). Levi, Musatti, Piredda, and Sechi (1984) investigated the differences among these groups when the subjects were required to generate a story from 4 picture cards and when the examiner then told a story using the same pictures and the children were required to retell it. The normal children and those with reading retardation showed improvement between the first and second versions with increases in lexical richness and narrative explicitness. The group of dyslexic children showed a marked improvement in terms of the indicators of complexity and in terms of lexical richness, yet improvement of narrative explicitness was negligible. They concluded that this 
behavior indicated the inability to grasp the deep narrative structure of the story as told by the examiner.

\section{Cohesion}

Researchers have not only looked at story complexity, but have also studied the adequacy of narrative cohesion. Liles (1985) adopted Halliday and Hasan's descriptions of cohesion in English and developed a procedure for measuring cohesion in children's narratives. Liles (1985) found that on a retelling story task (using a video), language disordered children (7.610.6 years old) differed in cohesive organization and cohesive adequacy, using less personal reference ties and more demonstrative and lexical ties than normal language children. And their narratives contained a higher percentage of both incomplete and error ties. In general, they showed poorer use of cohesive conjunctives (Liles, 1985). Schneider (in Donahue \& Bryan, 1984) found similar results with learning disabled adolescents. Graybeal (1981), Johnston (1982), Liles (1985), and Liles and Merrit (1985) found that language disordered children comprehend and produce logical relationships across events less well than normal language children (Liles, 1987). Story retelling of dyslexic boys contained only half as many temporal and causal relations (Weaver \& Dickinson, 1979); and, on fictional stories, learning disabled children produced fewer casual relationships than their normal language peers (Roth \& Spekman, 1986). 
In general, children with language learning difficulties tend not to adequately produce narratives containing linguistic markings that code temporal and causal relationships (Roth, 1986).

\section{Information}

In terms of narrative length and information conveyed, Roth and Spekman (1986) found that on fictional stories (given a topic), learning disabled children (ages 8-13.11) told shorter stories with fewer units of meaning. Fry et al. (1970) and Smiley et al. (1977) found that in retellings (picture tasks), poor readers produced proportionally fewer of the important aspects of the stories than the good readers (Garnett, 1985). Similarly, Weaver and Dickinson (1979) studied the story retelling of dyslexic boys (ages 10.3 \& 13.9) and discovered that less information was recalled. A study by Feagans and Mckinney (1982) investigated retelling abilities of learning-disabled children ( 6 \& 7 years old) and found that they recalled fewer events, mixed up the order of events, and specifically had trouble recalling the final events of the stories. From similar results with 7-9 year old language impaired children, Graybeal (1981) concluded that story retelling deficits reflected an inefficient or disorganized use of memory strategies (Garnett, 1986).

In general, children with language learning difficulties produce narratives that are shorter and contain less information and detail. 
Lexical Diversity

Specifically with regard to lexical diversity, researchers have found that in retellings, poor readers used more restricted vocabulary (Garnett, 1985). Roth and Spekman (cited in Kamhi \& Catts, 1989) stated that the expressive vocabulary skills of reading disabled students, assessed on structured definitional tasks, indicate that the definitions produced by reading disabled children are less accurate and less sophisticated than their normal reading peers. A semantic deficit may not only affect reading comprehension and determination of word meaning, but also would be expected to inhibit the understanding and use of figurative language (Roth \& Spekman, cited in Kamhi \& Catts, 1989). Thus, lexical diversity may be influenced by semantic development and flexibilitiy.

Previous study of subjects in this study

one study in particular has looked at many of these different aspects or measures of narrative ability discussed thus far in this chapter. Paul and smith (1991) investigated the narrative skills in the same subjects studied here when the subjects were 4 years old. Subjects were given the Bus Story Test (Renfrew, 1969), a story retelling task. on measures of cohesion, sequence, informational units, and lexical diversity, children with chronic language delay performed significantly more poorly than their normal peers. A third group of children whose language had been delayed when 
they were toddlers but who caught up by age 4 were not significantly different from the normal speakers on any of the measures of narrative ability. Interestingly, they were not significantly different from the chronic language delayed group either in terms of cohesive adequacy, lexical diversity, and number of informational units expressed. Of interest would be whether the late developing language group maintains their language gains in elementary school or whether they are still at risk for language and reading problems. Scarborough and Dobrich (1990) found in their longitudinal research on the development of children with early language delay that while there may be a short-term recovery from early language delay by age 5 to 6 , a long-term problem may still persist during the school age years and beyond. With the assumption that normal language development proceeds in a stepwise fashion, with spurts in the third and sixth years of life separated by an extended plateau, Scarborough and Dobrich (1990) suggested that the early language delay children seem to catch up to their normal language peers who remain on an extended plateau. However, differences become more obvious when the normal children undergo the next developmental language spurt and the early language delay children lag behind once again. This research indicates that children with early language delay are still at risk for long-term language problems. 
Summary

Research to date indicates that narratives of children with language difficulties contain less information and fewer adequate linguistic markers, are shorter with restricted vocabulary, and are less structurally complex.

\section{BACKGROUND TO CURRENT STUDY}

of crucial importance to this study, Westby (in Kamhi \& Catts, 1989) has divided spontaneous story generation into two separate tasks: developing an original story with no stimulus provided, and describing the story in a wordless picture book. These two tasks require different skills. Westby (1989) suggests that a relatively quick and easy way to assess a child's ability to recognize and comprehend schema knowledge is to have the child tell a story from a wordless picture book. This kind of task requires a child to 1) recognize what the characters are doing on each page, 2) realize the relation between the events on adjacent pages, 3) realize the relations among all the actions in the book, and 4) understand temporal sequencing, physical and psychological cause-effect relations, and plans and reactions of characters. The amount and accuracy of factual and inferential information conveyed, and the cohesive organization and adequacy may be analyzed. This type of task does not assess a child's ability to generate story content schema and organize it into a text grammar structure. 
There have been no studies done thus far that have investigated narratives produced from wordless picture books by normal and language delayed children. And as Westby (1989) points out, if students are unable to produce narratives from wordless picture books, then they will be unable to produce a coherent story themselves when no stimuli or stimuli with very limited structure are provided. And since so much of the school-based information takes the form of narration and requires students to retrieve and organize schematic knowledge with minimal environmental support, narrative performances from wordless picture books by young school-age children may likely help to predict success or failure in the school language setting (Feagans, 1983; Westby, 1989). Therefore, research is needed in the area of narrative performance from a wordless picture book measuring a variety of narrative skills, all of which are necessary for a mature, unified story. This study provides information about narrative skills of kindergarten children with differing rates of language development (normal, impaired, and late developing) on measures of story length, lexical diversity, cohesion, information, and narrative stage assignment. As discussed earlier in this chapter, these measures have proven to indicate significant differences between normal language children and children with language difficulties on retelling and spontaneous story tasks. Differences in narrative ability that can be related to early language characteristics may be 
useful in making diagnostic and prognostic decisions for young children with slow expressive language development. 
CHAPTER III

METHODS AND PROCEDURES

SUBJECTS

The subjects for this study are involved in the Portland Language Development Project (PLDP), a longitudinal study of early language delay.

Subject Description at In-take: Age 2

The subjects were recruited from local pediatric clinics and from newspaper ads when they were 20-34 months of age (Appendix C). Approval was received from the Human Subjects Research Review Committee for the PLDP and for this specific study (Appendix D1 \& D2). The parents of the subjects signed a permission form and were requested to fill out questionnaires providing the following information: parental occupation, child's birth date, the number of different words the child uses, and whether or not the child puts words together to form short sentences (Appendices $E \& F$ ). Two diagnostic groups were identified at intake: normal and late talkers (LT). The subjects were considered normal if the parents reported use of more than 50 different words on the Language Developmental Survey (LDS) (Rescorla, 1989) (Appendix G) . The subjects were considered LT if they used fewer than 
50 different words as reported by parents on the LDS. The groups were matched for chronological age and were matched as closely as possible for race, sex, and socioeconomic status (SES). The SES was based on a 2 factor index combining occupational and education status of the parent(s), yielding weighted scores of 1 to 5 , with 1 being the highest SES level and 5 the lowest (Myers \& Bean, 1968).

All subjects passed a hearing screening at $25 \mathrm{~dB} \mathrm{HL}$, and all scored 85 or more on either the Bayley Scales of Infant Development (Bayley, 1969) or the Stanford-Binet Intelligence Scale (Terman \& Merril, 1960) depending on age. None of the subjects had known physical handicaps, mental retardation, or autism.

All the children in the study were given an individual, complete language assessment again at age three, four, and when they were enrolled in a kindergarten program.

Table I displays the demographic information of the diagnostic groups at intake and at kindergarten follow-up, including mean ages at intake, SES, \# words spoken at intake, and mean ages at follow-up.

Follow-up Assessment: Kindergarten

Fifty-two kindergarten children (aged 67-78 months) were seen during their kingergarten year, 25 identified as normal at age two and 27 identified as LT.

The subjects were seen in a clinic room at Portland state University as part of their kindergarten evaluation (as part 


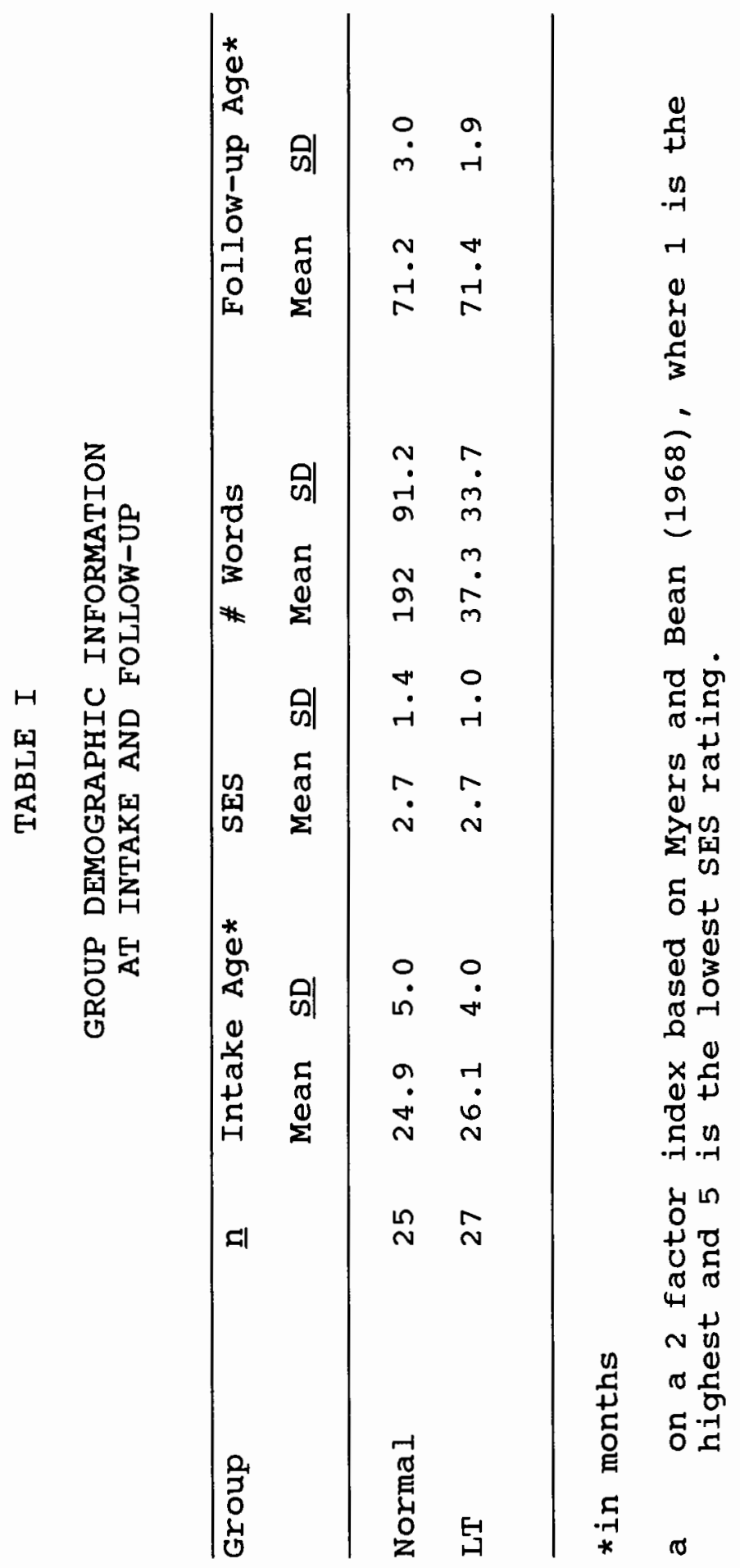


of the on-going longitudinal study). At this evaluation, a spontaneous speech sample was collected from each subject while engaged in free play with his/her parent. A narrative task was also administered.

Each subject's spontaneous language sample was scored for grammatical developement according to the DSS criteria (Lee, 1974) (Appendix A) .

Criteria for Language Diagnostic Group Assignment: Kindergarten

Subjects were assigned to three diagnostic groups at kindergarten age on the basis of their DSS scores and original diagnoses. These three groups were defined as follows:

1. The subjects were considered to be normal if they used more than 50 different words at age 20-34 months as reported by the parents on the LDS and also scored 6.35 or above (10th percentile for age 5.0) on the DSS (Lee, 1974) at kindergarten age, calculated from the free speech sample.

2. The subjects were considered to have a history of expressive language delay $(\mathrm{Hx})$ if they were identified as LT at age 20-34 months because they produced fewer than 50 words, but at kindergarten age scored 6.35 or above (10th percentile for age 5.0) on the DSS (Lee, 1974) calculated from the free speech sample.

3. The subjects were considered to be expressive language delayed (ELD) if they were identified as LT at age 20-34 months because they produced fewer than 50 words, and 
also scored below 6.35 (10th percentile for age 5.0) on the DSS (Lee, 1974) at kindergarten age, calculated from the free speech sample.

The preceding selection criteria resulted in the following diagnostic grouping: 25 children assigned to the normal language (NL) group (chronological age at kindergarten $=67-78$ months); 17 children assigned to the $\mathrm{Hx}$ group (chronological age at kindergarten $=69-75$ months); and 10 children assinged to the ELD group (chronological age at kindergarten $=68-76$ months $). \quad($ Table II).

\section{PROCEDURES}

For the narrative task, each subject was instructed that he/she would tell a story. The examiner and the child were seated at a small table across from each other. A microphone (Sony ECM-144 Electret condenser lavaliere) was attached to the child's shirt, and a tape recorder (Sony Dictator) Transcriber BM-88, Sony dictation cassette DC-30N) was turned on after the instructions were given. The examiner held a wordless picture book, A Boy, a Dog, and a Frog (Meyer, 1967), and gave the following instructions (suggested by Westby, 1984):

Here's a book with pictures that tell a story. I want you to look at the pictures and tell me the best story you can. I can't see the book so make sure to tell the story so I understand it. Make it the kind of story we would read in a book. 


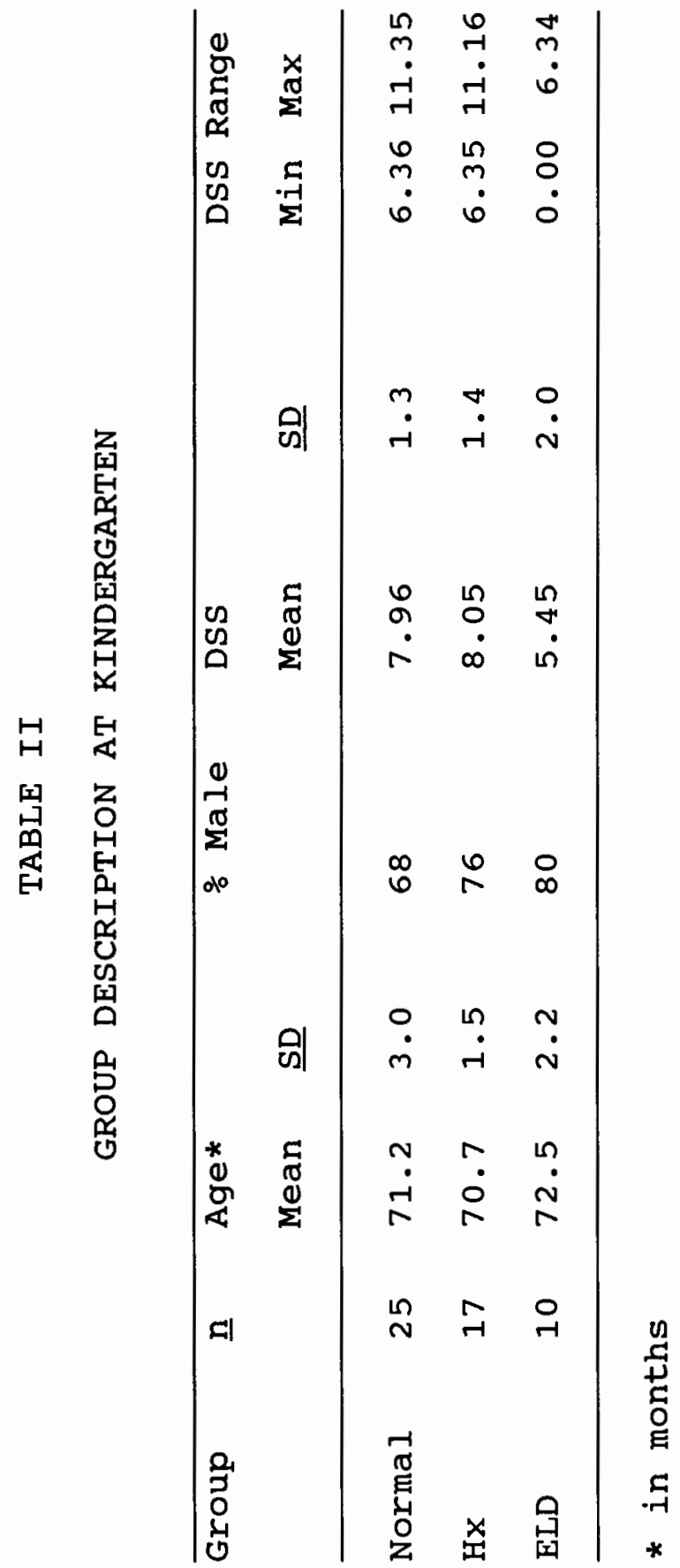


The examiner then handed the book to the child, making sure the child started on the first page of the story. The examiner says nothing while the child tells a story, prompting non-committally if necessary: "Ye-e-es" or "And then..." or "So..." or repeating the last sentence spoken with an upward intonation.

Following the narrative sample, speech samples were recorded on audiotape (approximately 15 minutes per child) during free play between each parent-child group. The parent was instructed to "play with your child as you do at home." The toys used for the free play session were Fisher-Price people, furniture, house, and town. This sample was used to compute DSS for the group assignments described on pages 2324 .

DATA ANALYSIS

The free speech samples and the narrative samples were transcribed orthographically (with bound morphemes indicated) directly from the audiotapes into the systematic Analysis of Language Transcript (SALT) computer program (Miller \& Chapman, 1986) by this investigator and two other graduate research assistants.

Six measurements of narrative ability were calculated on each narrative sample: MLU per T-unit, Type-Token Ratio, Lexical Richness, Cohesion, Information, and Narrative Stage Assignment. These variables were thought to survey a range of 
abilities necessary to producing a comprehensive narrative. Some were drawn from the literature on narrative development, and some were devised from the interest of this investigator.

\section{$\underline{\text { MLU per T-unit }}$}

The mean length of utterance in morphemes is a general indicator of structural development of the productive language of children (Miller, 1981). To calculate the MLU, the children's utterances were divided into T-units and entered into the SALT program. The SALT program automatically calculated the MLU per T-unit for each narrative sample.

According to scott (1981, p. 55):

The T-unit consists of a main clause with all subordinate clauses or nonclausal structures attached to or embedded within. All main clauses that begin with coordinating conjunctions AND, BUT, OR initiate a new T-unit unless there is co-referential subject deletion in the second clause.

New T-units that were a continuation of an utterance were coded $[\mathrm{T}]$ before the first word of the new T-unit. Furthermore, strong and Shaver (1991) developed their own rules for counting T-units and words, and these were followed in this study (Appendix $H$ ).

The use of T-unit segmentation assures that the MLU is not skewed by run-on sentences conjoined with "and" that are typical of young children's speech. 
Type-Token Ratio (TTR)

According to Templin (1957) "the type-token ratio indexes lexical diversity" (Miller, 1981, p.41). The type-token ratio is the result of dividing the total number of words used (tokens) into the total number of different words (types) (Miller, 1981). These values were automatically calculated using SALT for each narrative sample.

\section{Lexical Richness}

A computer program developed by Ann Nockerts (1991) to be used in conjunction with the SALT program calculated the total number of unusual word types used by each child in his/her narrative that were not found on Wepman and Hass' list of the 500 most common words used by 6 year olds (Appendix I). This measure is another way to look at lexical diversity.

\section{Cohesion Score}

Each subject's narrative was coded for the use of cohesion and a cohesive adequacy score was calculated, indicating the percentage of complete ties used. The procedure outlined by Liles (1985) for identifying cohesive markers and adequacy of cohesion was modified (Appendix J). After reading the entire transcript, the examiner reread the narrative, line by line, circling the cohesive markers. Any word was a cohesive marker if the listener had to look outside that sentence for the completed meaning. If the information referred to was found within the sentence, the word was not a 
cohesive marker. Whenever two or more conjunctions were found within a sentence, the examiner selected the conjunction that was the most complex--being causal, followed by adversative, temporal, and additive.

After circling all the cohesive markers in a narrative, the examiner recorded on a score sheet the line number of the cohesive marker in the transcript, the cohesive marker, the line number and word to which the cohesive marker referred, and whether the tie was complete or noncomplete. To be complete, the information referred to by the cohesive marker was easily found. To be noncomplete, the information was either not provided in the text or the reference was ambiguous. The percentage of complete ties used was calculated for each narrative by dividing the number of complete ties by the number of complete and noncomplete ties.

\section{Information Score}

An information score was determined for each narrative, reflecting the number of relevant pieces of information the child included in the story, out of 26 essential propositions determined by the investigator. The investigator and 2 other graduate researchers involved with the longitudinal study independently went through the picture book and recorded the main propositions which were necessary to achieve continuity in the story. The propositions that were in three way agreement were termed essential. Those 26 propositions became the scoring criteria (Appendix $\mathrm{K}$ ). The examiner compared the 
contents of each child's story to the scoring criteria, and the total number of these 26 propositions expressed in each subject's narrative was the information score for each subject. This information score had a possible range of 0-26.

\section{Narrative stage Assignment}

Each narrative was assigned to a stage of narrative development, based on Applebee's (1978) stages, as outlined in Chapter two. Applebee's (1978) stages were modified for the purposes of this study. Due to problems in reliably distinguishing focused from unfocused chains, the focused and unfocused chains were combined into one stage for this study and referred to as a "chain". This study identified five narrative stages: heap, sequence, primitive narrative, chain, and true narrative.

Assignment to a narrative stage involved the examiner reading the entire narrative and making a global judgment as to whether the narrative was a heap, sequence, primitive narrative, chain, or true narrative. A story consisting of simple labeling or description of activities without organization was identified as a heap story. The following is an example of a heap story gathered in this study:

Mercer went out his home.

Then he go to the playground.

Then he found a frog.

Then he fell off the cliff.

Then he dead.

And then Mercer called the ambulance, then he took

him to the hospital.

The he go to the... 
The he $\mathrm{x} \times \mathrm{x}$.

Then he put his nose in his face.

Then his blood came out.

Then he fell down in the water.

Then he on the police headquarters top of the tree. Then he $\mathrm{X} X$.

Then I fell down.

But I have stay in bed.

He mad at the friend Mitty.

He "Go home sister."

Then he fell down the water.

Then he catched that frog.

Then he "Blah."

Then he got into the drap.

It's a bad guy.

Then he called the police.

Then he rested.

And then he goed in jail.

Then that's the jail.

And his sister is feeling sad.

Then he found a big rock.

Then he went home by hisself.

Then Mercer came back.

Then he surprise.

Then he walk home.

Then he eat lunch.

Then he hungry.

Then the frog is...

Then his mama is mad.

Then Mercer "Mercer."

Then he happy.

A story consisting only of a description of a character's activities was identified as a sequence. Following is an example of a sequence story gathered in this study:

$\mathrm{x}$ little boy.

Tree, frog.

Tree, person, dog, bucket, and tree that he climbing on, bucket and dog.

They fell off.

With a bucket $x$ dog, person.

Then they ran down the hill and trip down.

Then they fell into the water and the bucket did... And then the bucket came onto his head.

And then the frog was happy.

And then the dog was swimming.

Then there's a pail on his head.

And then there's a leaf that the frog jumped off. Then there was... 
The boy tried to catch the frog except he jumped. Then there was a dog happy.

Then there's a frog sitting on the tree.

And then the boy pointed for the dog to go.

So they went to the tree that fall into the water where the frog is.

And then the boy caught the dog.

And he tried to catch the frog.

Lookit, the dog's in the net!

He thought he caught the frog.

And then there was a boy yelling at the frog.

And then the do go.

Then the frog was sad.

And when the dog was happy that they're all going away.

Then they were walking with he mad and the dog sad. And then he was alone.

Then he saw footprints all the way through the house.

Then into the closet.

And then into the bathtub.

A story was identified as a primitive narrative if the child made some cause-effect or temporal relationships among events, yet lacked an overall logical action plot. Following is an example of a primitive narrative gathered in this study:

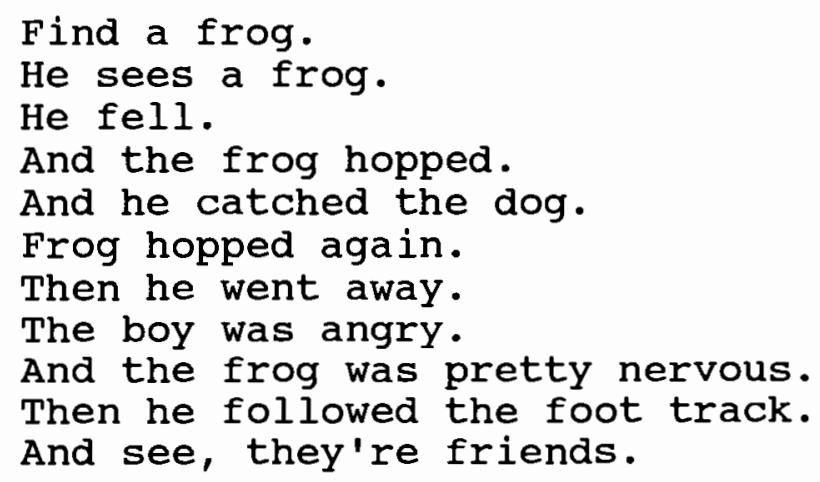

A story containing some character motivation, some causeeffect and temporal linking, and a sense of plot through logical sequencing of action; yet, lacking a clear problem and resolution in the plot structure was identified as a chain. Following is an example of a chain gathered in this study: 
A boy went for a walk with his dog to fetch water and catch fish.

There was a frog.

He caught the frog.

The dog ate the frog.

The boy fell in because he tripped on the dog.

The dog fell in too.

The frog went "oopsie."

The frog went "I'm sorry."

The dog went and sniffed the frog.

The frog hopped onto a lilypad.

The dog and the boy hopped onto a lilypad.

They drowned at it.

They didn't drown.

The frog fell off.

Whoa!

And the boy tried to catch the frog.

But the frog fell off.

And the boy actually caught the dog.

The frog climbed onto a rock.

The boy called him.

The boy threw a rock at him.

The boy and the dog wagged his tail.

They went away.

The frog was sad.

The boy still went away.

The frog, "I could still see them."

The frog sad there alone, $\mathrm{X} X$.

The frog followed him.

He followed him into his house.

He smelled water.

And the frog was on the dog's head.

And a story containing elaborate character development and including all the basic story grammar parts, especially describing the resolution and shifts in characters' psychological states, was identified as a true narrative. Following is an example of a true narrative gathered in this study:

There was a little boy.

And he wanted to get a frog.

And he brought his dog.

He saw a frog in the pond.

He ran to catch it.

But he tripped over a log.

And he fell in the water. 
When he came out, he had his bucket on his head. He tried to get the frog with the bucket on his head.

But the frog jumped over to a $10 \mathrm{~g}$.

He told his dog to go try to get the frog.

He put his dog on one side.

And he got on the other side when the frog wasn't looking.

He almost caught the frog.

But instead, he caught his dog.

When he saw what he caught, he was mad.

The frog was mad that he almost got him.

The little boy, he yelled to the frog.

The frog sat on a rock.

Then the boy went home and left the frog.

The frog was sad alone.

Then he followed the boy's footprints, not dog prints, until he got into the house.

Then he kept following them into the bathroom where the little boy took a bath.

"Hi," he said to the frog.

Then the frog jumped in the tub.

The End.

Each narrative was assigned a number from 1 to 5 to indicate stage assignment, 1 being a heap and 5 being a true narrative.

Reliability

Approximately $10 \%$ of the narratives and language samples were randomly selected and transcribed by an additional trained researcher (directly involved with the longitudinal study) who was present at the time of the narrative task and language sampling.

For each free speech sample, a point to point comparison of words transcribed was done on 10 percent of the child utterances transcribed. The number of words in agreement was divided by the total number of words transcribed, and an agreement score of $98 \%$ was derived. Approximately $13 \%$ of the 
spontaneous speech samples were scored for reliability of DSS scoring. A point to point comparison was done for sentence scoring, dividing the total number of categorical points in agreement by the total number of categorical points in agreement and disagreement, and interrater reliablity was $92 \%$.

For each narrative sample, a point to point comparison of words transcribed was done for every utterance. An agreement score of $98 \%$ was derived. The narrative samples were scored by an additional researcher for the narrative measures of cohesion, information, and narrative stage assignment. Scores on each measure of narrative ability were arrived at independently by two researchers, and interrater reliability was determined by percentage of agreement for each measurement. Approximately $42 \%$ of the narrative samples were scored for reliability of the narrative stage assignment, yielding an interrater reliability score of $91 \%$. Approximately $13 \%$ of the narrative samples were scored for reliability of information scoring, dividing the total number of informational points in agreement by the total number of informational points in agreement and disagreement, yielding an interrater reliability score of $95 \%$. Approximately $10 \%$ of the narrative samples were scored for reliability of cohesion scoring, yielding an interrater reliability score of $91 \%$ for identification of cohesive markers (dividing the total number of cohesive markers identified in agreement by the total number of cohesive markers identified in agreement and 
disagreement) and $96 \%$ for identification of cohesive adequacy (dividing the total number of complete and noncomplete judgments in agreement by the total number of complete and noncomplete judgments in agreement and disagreement).

\section{Statistical Analysis}

The design for this study was a complex group design with a 3 level independent variable (group diagnosis) and 6 dependent variables. Descriptive statistics (range, mean, and standard deviation) were calculated for all the dependent variables. The inferential parametric statistic ANOVA (threeway analysis of variance) was calculated on each dependent variable, separately, except for the narrative stage assignment (since it is based on an ordinal scale) to determine whether the differences among the groups' performances were significant for each variable. If a significant difference (chosen alpha level is .05--greater chance of finding a real difference if one exists) was found among groups on any of the dependent measures, then a post-hoc multiple comparison among pairs of means was done using a Tukey Multiple Comparison Test on that variable to determine which groups were significantly different from each other. An analogous inferential non-parametric statistic, Kruskal-Wallis one-way analysis of variance, was used to determine if there were significant differences among the 3 groups on the narrative stage assignment. 


\section{CHAPTER IV \\ RESULTS AND DISCUSSION}

\section{RESULTS}

The specific objective of this study was to determine whether there are differences in spontaneous narrative ability (using a wordless picture book) in kindergarten children that can be related to language characteristics at age two.

The research question asked was: on a spontaneous narrative task, given a wordless picture book, do the narrative skills of children with differing rates of language development (normal, impaired and late developing language) differ significantly from each other's on the six different measures of narrative skill examined: MLU per T-unit, TTR, Lexical Richness, Cohesion, Information, and Narrative stage Assignment.

The range, mean and standard deviation of each group for each of the dependent measures were computed. These are shown in Table III.

The data were analyzed to determine whether significant differences existed between the language diagnostic groups of normal, history of expressive language delay $(\mathrm{Hx})$, and 
TABLE III

RANGE, MEAN, AND STANDARD DEVIATION OF EACH GROUP FOR EACH OF THE DEPENDENT MEASURES

\begin{tabular}{llcccc}
\hline \multirow{2}{*}{ Measure } & Group & Minimum & Maximum & Mean & $\underline{\text { SD }}$ \\
\hline \multirow{2}{*}{ MLU/T-unit } & & & & & \\
& $\mathrm{N}$ & 5.2 & 9.4 & 7.2 & 1.0 \\
& $\mathrm{Hx}$ & 4.6 & 9.7 & 6.9 & 1.3 \\
& ELD & 5.4 & 8.5 & 6.6 & 1.2 \\
TTR & $\mathrm{N}$ & .31 & .56 & .42 & .07 \\
& Hx & .30 & .59 & .43 & .09 \\
& ELD & .33 & .54 & .41 & .06
\end{tabular}

Lexical Richness

Unusual Word Types

$\begin{array}{lllll}\mathrm{N} & 8.0 & 31.0 & 15.5 & 6.1 \\ \mathrm{HX} & 6.0 & 20.0 & 11.0 & 3.5 \\ \text { ELD } & 5.0 & 18.0 & 10.3 & 4.6\end{array}$

Cohesion

$\%$ Complete ties

$\begin{array}{lrrrr}\mathrm{N} & 39.0 & 100.0 & 84.7 & 16.6 \\ \mathrm{Hx} & 22.0 & 100.0 & 76.7 & 23.4 \\ \mathrm{ELD} & 5.0 & 100.0 & 62.1 & 31.7\end{array}$

Information

$\begin{array}{lrrrr}\mathrm{N} & 6.0 & 20.0 & 11.9 & 3.2 \\ \mathrm{HX} & 5.0 & 16.0 & 11.4 & 3.1 \\ \mathrm{ELD} & 1.0 & 15.0 & 9.1 & 4.7\end{array}$

Narrative Stage Assignment

\begin{tabular}{lllll}
$\mathrm{N}$ & 2.0 & 5.0 & 4.1 & .8 \\
$\mathrm{HX}$ & 2.0 & 5.0 & 3.8 & .7 \\
$\mathrm{ELD}$ & 1.0 & 4.0 & 3.1 & 1.2 \\
\hline
\end{tabular}


expressive language delayed (ELD) on measures of the spontaneous narrative task in order to answer the research question.

The Bartlett Test for Homogeneity of group variables was done on each of the dependent measures, and the populations were found to be approximately normally distributed, with the exception of the narrative stage assignment.

Because of the narrative stage assignment measure did not meet the assumptions for parametric statistics and because it is based on an ordinal scale, a nonparametric Kruskal-Wallis test was computed to test for differences among pairs of means.

Table IV displays the $\underline{F}$ values for those variables which met the assumptions for parametric statistics, the Tukey Test results for those variables which had a significant $\underline{F}$ value (at the .05 significance level), and the Kruskal-Wallis test statistic result for the measure of narrative stage assignment.

No significant differences were found among the groups on the following measures: mean length of utterance per T-unit, the type-token ratio, and the information score. significant differences were found among groups on the following measures: the number of unusual word types used, the percentage of complete ties used, and the narrative stage assignment. 


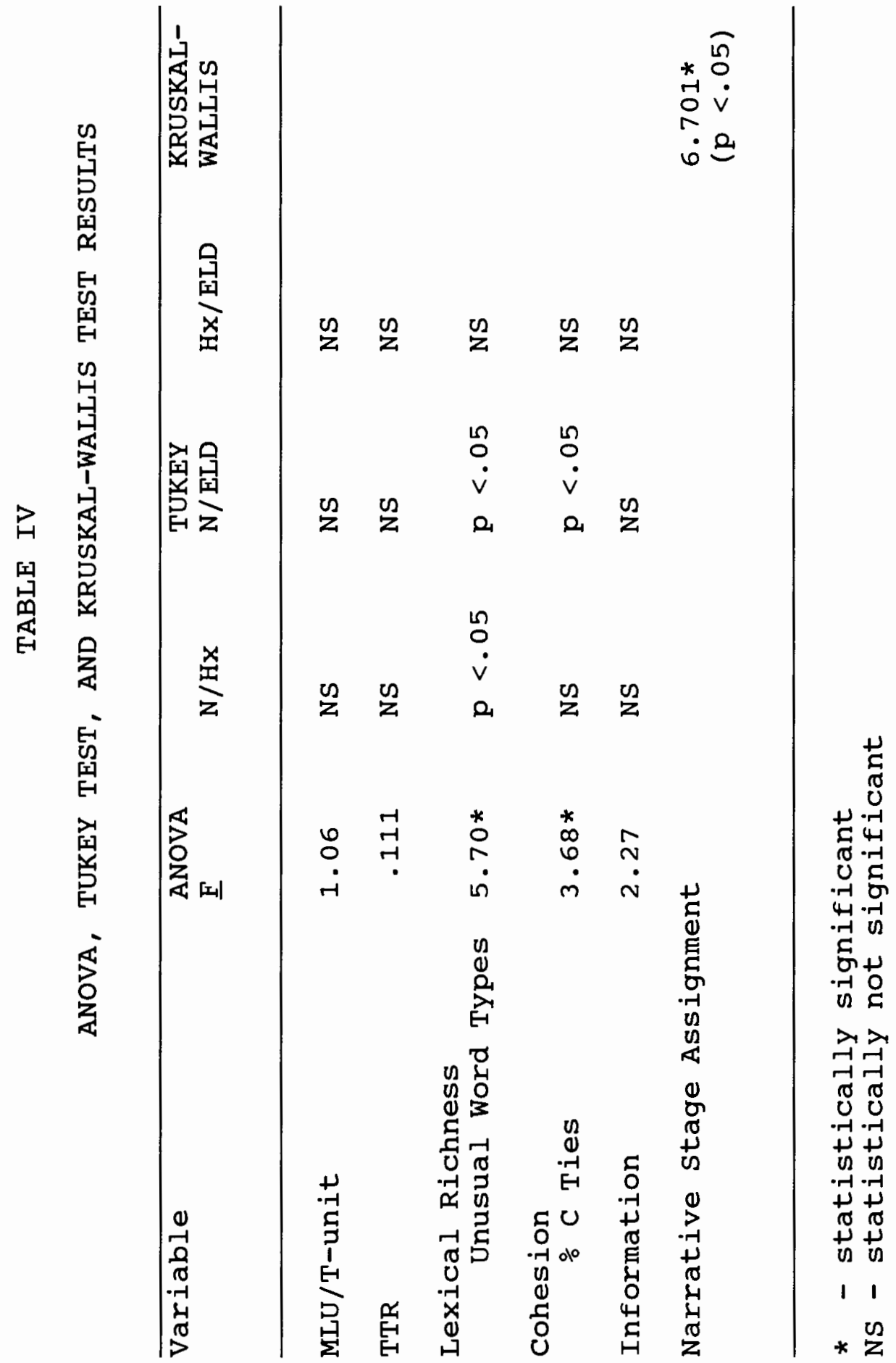


Lexical Richness: number of unusual word types

A significant difference $(p<.05)$ was found among groups. A Tukey Test showed the normal language group performed better than both the $\mathrm{Hx}$ and the ELD groups. This indicates that $\mathrm{Hx}$ children and those with ELD used fewer unusual word types (words that do not appear on Wepman \& Hass' list of the 500 most common words of 6 year olds) on a spontaneous narrative task than children whose language development has been normal.

As shown by the means in Table III, the Hx group was not significantly better than the ELD group on this measure.

\section{Cohesion: percentage of complete ties}

A significant difference $(p<.05)$ was found among groups. A Tukey Test showed the normal language group performed better than the ELD group. This indicates that those children with normal language development performed significantly better at using linguistic markers to adequately link ideas than the ELD group. No significant difference was found between the normal language group and the $\mathrm{Hx}$ group or between the $\mathrm{Hx}$ and the ELD group. The Hx group appears to fall between the other two groups on this measure and is not significantly different from either.

\section{Narrative stage assignment}

The data collected did not fit the assumptions for an ANOVA test, in that it was not normally distributed and was measured on an ordinal scale; so a nonparametric test, the 
Kruskal-Wallis, was completed. A significant difference ( $p<.05$ ) was found among groups. Additional comparisons of the significance of differences between pairs of means are not possible with this statistic. Yet, from the means in Table III, this suggests that in terms of overall narrative maturity, the normal language group performed at a higher level than the ELD group. From the means in Table III, the Hx group performed somewhere in the middle, more like the normal language group.

\section{DISCUSSION}

The data collected to answer the research question regarding the performances of three groups with differing rates of language development, shows that using a wordless picture book, no significant differences were found among the three language groups in terms of MLU per T-unit, TTR, and information score. The fact that these measures did not produce any significant differences among the three groups may be attributed to the presentation of the narrative task which was supported by pictures which contained the basic story grammar. The significant differences found between the normal language group and the ELD group were on the measures of lexical richness, cohesion, and narrative stage assignment, which are more sensitive measures of language maturity and sophistication. These higher level language skills, on which discourse and reading skills rely, would be expected to show 
a difference between these two groups.

A significant difference was found between the normal language group and the ELD group on the measure of lexical richness-the number of unusual word types. The normal language group used a significantly greater number of unusual words, those not commonly used by 6 year olds, in their narratives than the ELD group. This may support the finding that the normal language group has a greater overall story maturity and may be less tied to structural/syntactic elements and freer to use more diverse and rich language in their narratives.

Furthermore, a significant difference was found between the normal language group and the ELD group on the measure of cohesion-the percentage of complete ties used. The normal language group performed significantly better at using linguistic markers to adequately link ideas than the ELD group. The ELD group's use of cohesive markers more likely led the reader to ambiguous or erroneous information.

In terms of the measure of narrative stage assignment, a significant difference was found among groups. This would suggest that the normal language group's narratives reached a higher level of overall maturity in terms of creating a true story grammar than the ELD group. The ELD group tended to describe some temporal and causal relationships in the story; however as a group, their narratives lacked a strong, logical plot with character motivation and story resolution. 
No significant differences were found between the $\mathrm{Hx}$ group and the ELD group on any dependent measure. One must also consider the fact that no significant differences were found between the $\mathrm{Hx}$ group and the normal language group either, except for the measure of lexical richness--the \# of unusual word types.

Because of the statistical limitations placed on the measure of narrative stage assignment, one can only assume from the data that the Hx group's overall story maturity falls somewhere between the normal language group and the ELD group, as it does on the cohesion and lexical richness measures.

Because significant differences were not found between the normal language group and the $\mathrm{Hx}$ group on the higher level language skills of cohesion and narrative stage, one may conclude that children who do not meet the criteria for normal expressive language at age 20-34 months may catch up to perform similarly to peers whose expressive language at age 20-34 months was normally developing. However, the data indicates that the performance of the Hx group falls somewhere between the performance of the normal language group and the ELD group and is not different enough to distinguish this group from either of the others. Since they are not significantly worse than the normal group and are not significantly better then the ELD group, the Hx group may still be at risk for later language-learning and reading problems. Perhaps the measures used were not sensitive enough 
to find the subtle differences, if any, that exist between the normal language group and the Hx group. For example, in terms of cohesion, identifying the types of cohesive markers and the percentage of complete ties for each type of cohesive marker may prove significant. Furthermore with regard to narrative stage, identifying accuracy of inferences and the adequate use of relations among story events and ideas (cause-effect, character plans and reactions) may prove significant. 
CHAPTER V

SUMMARY AND IMPLICATIONS

SUMMARY

Researchers are finding that children's narrative language plays a critical role in guiding the transition between oral language and literacy (Roth \& Spekman, 1989; Westby, 1989). Narrative production demands higher level language skills to generate a mature, cohesive text using decontextualized language. Research has shown that narrative ability is the best predictor for normal speech and language development for preschoolers with language impairments (Bishop \& Edmundson, 1987), and these same skills are important for reading comprehension and school success.

The purpose of the present study was to compare the narrative ability of kindergarten children with differing rates of language development. The original group size was 25 children with normal expressive vocabulary size at age 20-34 months, and 27 children whose expressive vocabulary size fell below the normal range at 20-34 months (referred to as "Late Talkers" or LT) .

All the children were re-examined at kindergarten age. Each child was audiotaped producing a spontaneous narrative using a wordless picture book, and a spontaneous, 
conversational language sample.

When the spontaneous, conversational language samples were scored for syntactic complexity with Lee's (1974) Developmental Sentence Score (DSS), 17 (63\%) of the original LT had scores in the normal range and were reclassified as "History of Expressive Language Delay" ( $\mathrm{Hx})$. The remaining 10 (37\%) who continued to fall below the normal range were now classified as "Expressive Language Delayed" (ELD) .

The narrations produced by all the children were scored on 6 measures: Mean Length of Utterance per T-unit, TypeToken Ratio, Lexical Richness, Cohesion, Information, and Narrative Stage Assignment.

The data were analyzed to see if significant differences existed between the language diagnostic groups. On measures where an ANOVA test found a significant $\underline{F}$ value $(p<.05)$, a Tukey Test was done to determine where the significant difference among the groups existed.

No significant differences were found between the $\mathrm{Hx}$ group and the normal group on any measure, except lexical richness--the number of unusual word types. Also, no significant differences between the Hx group and the ELD group were found. Significant differences were found between the normal language group and the ELD group on the measures of lexical richness--the number of unusual word types, cohesion-the percentage of complete ties used, and narrative stage assignment, which are more sensitive measures of higher level 
language skills. In terms of these higher level language skills, it is not clear whether the Hx group may have subtle ongoing deficits not measured by this study or whether the skills of the Hx group have improved to a normal range but are not high enough to distinguish this group from the ELD group.

\section{IMPLICATIONS}

$\underline{\text { Research }}$

These data suggest that nearly two-thirds of those children whose expressive language did not meet normal language criteria at age 20-34 months, now at kindergarten age, have expressive language skills within the normal range as measured by the DSS. Paul and Smith's (1991) research data, based on the same longitudinal study as the present and using the same diagnostic criteria, found that at 4 years old, more than half the LT continued to have impaired language skills. It appears that more of the LT are catching up in terms of expressive production. Future research of interest would be to retest the $\mathrm{Hx}$ group in the first or second grade (the level at which normal children experience a second spurt in language development, Scarborough and Dobrich, 1990) on a similar narrative task and determine whether they have maintained their language gains as the school demands increase, or if subtle differences distinguish them from the normal language group on higher level language skills. Of particular interest would be whether narrative skills at early 
kindergarten age, using a wordless picture book, could be highly correlated with later reading skills at the older elementary grades and serve as a predictor of reading achievement.

Further research possibilities could address narrative tasks using the wordless picture books at kindergarten age to determine if such procedures are sensitive enough to yield subtle differences between the normal language group and the Hx group and between the Hx group and the ELD group. Research could aim at identifying more subtle language differences by measuring more specific higher level language skills such as: category of unusual words used (by noun, verb, adverb, adjective); category of reference used (pronoun, conjunction, lexical); category of conjunctive reference used (additive, adversative, temporal, causative); the number of inferences drawn (correct or false); and use and type of complex sentences.

\section{Clinical}

As a group, the ELD children fell below the normal parameters in measures of syntactic growth and also differed significantly from their normal peers in terms of lexical richness, use of cohesion, and overall story maturity. These characteristics are often associated with the school-age learning disabled child. The data suggests that the ELD group is at risk for further academic problems. Language intervention with those children whose language deficits still 
persist at kindergarten age is mandated.

In addition to working on semantic (vocabulary building) and syntactic goals at the sentence level, remediation should focus on the development of a basic story grammar knowledge, of inferential ability, and of cohesive skill. The ELD children may need the additional teaching and training of narrative skills in order to succeed with literacy.

The findings from this study suggest that even though the Hx group did not differ significantly from their normal language peers, except in terms of lexical richness, they did not differ significantly from the ELD group either. This indicates that the $\mathrm{Hx}$ group may still have subtle language differences and may be at risk for reading or learning problems in school, especially as the demands for proficiency in higher level language skills increase. The Hx group may need the additional teaching and training of narrative skills in order to succeed with literacy, as well.

Even though the $\mathrm{Hx}$ children may not receive direct intervention for possible higher level language deficits, regular classroom instruction may be modified at the kindergarten level (with consultation from the speech-language pathologist) to build stronger narrative skills. Garnett (1986) suggested that reading aloud, reflecting together, and probing feelings and motivations are important for giving children the fundamental support in the development of their narrative skills. More specific structures may be targeted 
that focus on a particular narrative skill (Paul, 1990). For example, in terms of story grammar, stories should be read to children at a level just above their own narrative stage. When reading stories, the teacher should break the story up into the basic parts and ask questions about each part. One should allow children to make up their own stories, using the wordless picture books, going through each step of the basic story grammar. In terms of developing inferential skill, when reading or telling stories, one should stop at several points in the story and ask the children to make predictions and then to judge them as good or bad. With the wordless picture books, children should make inferences about what will happen next before turning the page, and then afterwards judging their predictions. With regard to developing cohesive skill, when reading or telling stories, one should highlight the pronouns and draw lines to the referent. In terms of conjunction use and sentence elaboration, one should have children connect phrases with different conjunctions to see which is most appropriate, and then have them use the conjunctions in stories they make up using wordless picture books. 
REFERENCES

Applebee, A. N. (1978). The child's concept of story: Ages two to seventeen. Chicago: The University of Chicago Press.

Bishop, D. V. M. \& Edmundson, A. (1987) . Language-impaired 4year-olds: Distinguishing transient from persistent impairment. Journal of Speech \& Hearing Disorders, $\underline{52}$. 156-173.

Donahue, M. (1986). Linguistic and communication development in learning disabled children. In S. Ceci (Ed.), Handbook of cognitive, social, and neuropsychological aspects of learning disablities, 263-289. Hillsdale, NJ: Erlbaum.

Feagans, L. (1983). Discourse processes in learning disabled children. In J. McKinney \& L. Feagans (Eds.), current Topics in Learning Disabilities. Norwood, NJ: Ablex.

Feagans, L. \& Applebaum, M. I. (1986). Validation of language subtypes in learning disabled children. Journal of Educational Psychology, 78, 358-364.

Feagans, L. \& Short, E. J. (1984). Developmental differences in the comprehension and production of narratives by reading disabled and normally achieving children. Child Development, 55, 1727-1736.

Garnett, K. (1986). Telling tales: narratives and learningdisabled children. Topics in Language Disorders, 6, 4456 .

Halliday, M. A. K. \& Hasan, R. (1976). Cohesion in English. London: Longman Group Limited.

Johnston, J. (1982). Narratives: A new look at communication problems in older language-disordered children. Language, speech, and hearing services in schools, 13, $144-155$.

Kemper, S. \& Edwards, L. (1986). Children's expression of causality and their construction of narratives. Topics in Language Disorders, 7, 11-20. 
Levi, G., Musatti, L., Piredda, L. \& Sechi, E. (1984). Cognitive and linguistic strategies in children with reading disabilities in an oral storytelling test. Journal of Learning Disabilities, $17,406-410$.

Liles, B. Z. (1985). Cohesion in the narratives of normal and language disordered children. Journal of Speech and Hearing Research, 28, 123-133.

Liles, B. Z. (1987). Episode organization and cohesive conjunctives in narratives of children with and without language disorder. Journal of Speech and Hearing Research, $\underline{30}$, 185-196.

Miller, J. (1981). Assessing language production in children: Experimental procedures. Austin, Texas: Pro-ed.

Nelson, N. W. (1988). Reading and writing. In Nippold (Ed), Later language development. (pp. 97-125) Austin, TX: Pro-Ed.

Nockerts, A. (1991). Lexical Richness Computer Program. Oshkosh: WI.

Page, J. \& stewart, S. (1985). Story grammar skills in school-age children. Topics in Language Disorders, 5, 16-30.

Paul, R. (1990) Lecture at Portland State University. "Language disorders in school-age children."

Paul, R. \& Smith, R. (1991). Narrative skills in four year olds with normal, impaired, and late developing language. A paper presented at the 1991 Biennial Conference society for Research in Child Development. Seattle, WA.

Peterson, C. \& McCabe, A. (1983). Developmental psycholinguistics: Three ways of looking at a child's narrative. New York: Plenum.

Roth, F. (1986). Oral narrative abilities of learningdisabled students. Topics in Language Disorders, 7, 2130 .

Roth, F. \& Spekman, N. (1986). Narrative discourse: Spontaneously generated stories of learning-disabled and normally achieving students. Journal of Speech and Hearing Disorders, $\underline{58}, 8-23$. 
Roth, F. \& Spekman, N. (1989). Higher order language processes and reading disabilities. In Kamhi \& Catts (Eds.), Reading disabilities: A developmental lanquage perspective. (pp. 159-197). Boston: College Hill Press.

Scarborough, H. S. \& Dobrich, W. (1990). Development of children with early language delay. Journal of Speech and Hearing Research, 33, 70-83.

Scott, C. M. (1988). Spoken and written syntax. In Nippold (Ed), Later language development. (pp. 49-96) Austin, TX: Pro-Ed.

Stein, N. \& Glenn, C. (1979). An analysis of story comprehension in elementary school children. In $R$. Freedle (Ed.), New directions in discourse processing. Hillsdale, NJ: Erlbaum.

Strong, C. \& Shaver, J. (1991). Stability of cohesion in the spoken narratives of language-impaired and normally developing school-aged children. Journal of Speech and Hearing Research, 34, 95-111.

Sutton-Smith, B. (1986). The development of fictional narrative performances. Topics in Language Disorders, $7,1-10$.

Wepman, Joseph M. \& Hass, Wilbur. (1969). A spoken word count. Chicago: Language Resource Association.

Westby, c. (1984). Development of narrative language abilities. In Wallach \& Butler (Eds.), Language learning disabilities in school-age children. Baltimore, MD: Williams \& Wilkins.

Westby, C. (1989). Assessing and remediating text comprehension problems. In Kamhi \& Catts (Eds.), Reading Disabilities: A developmental language perspective (pp. 199-259). Boston: College Hill Press. 


$$
\text { APPENDIX A }
$$

\section{DEVELOPMENTAL SCENTENCE SCORE:}

SCORING CRITERIA

Lee, L. (1974) Developmental sentence analysis. Evanston, IL: Northwestern University Press. 


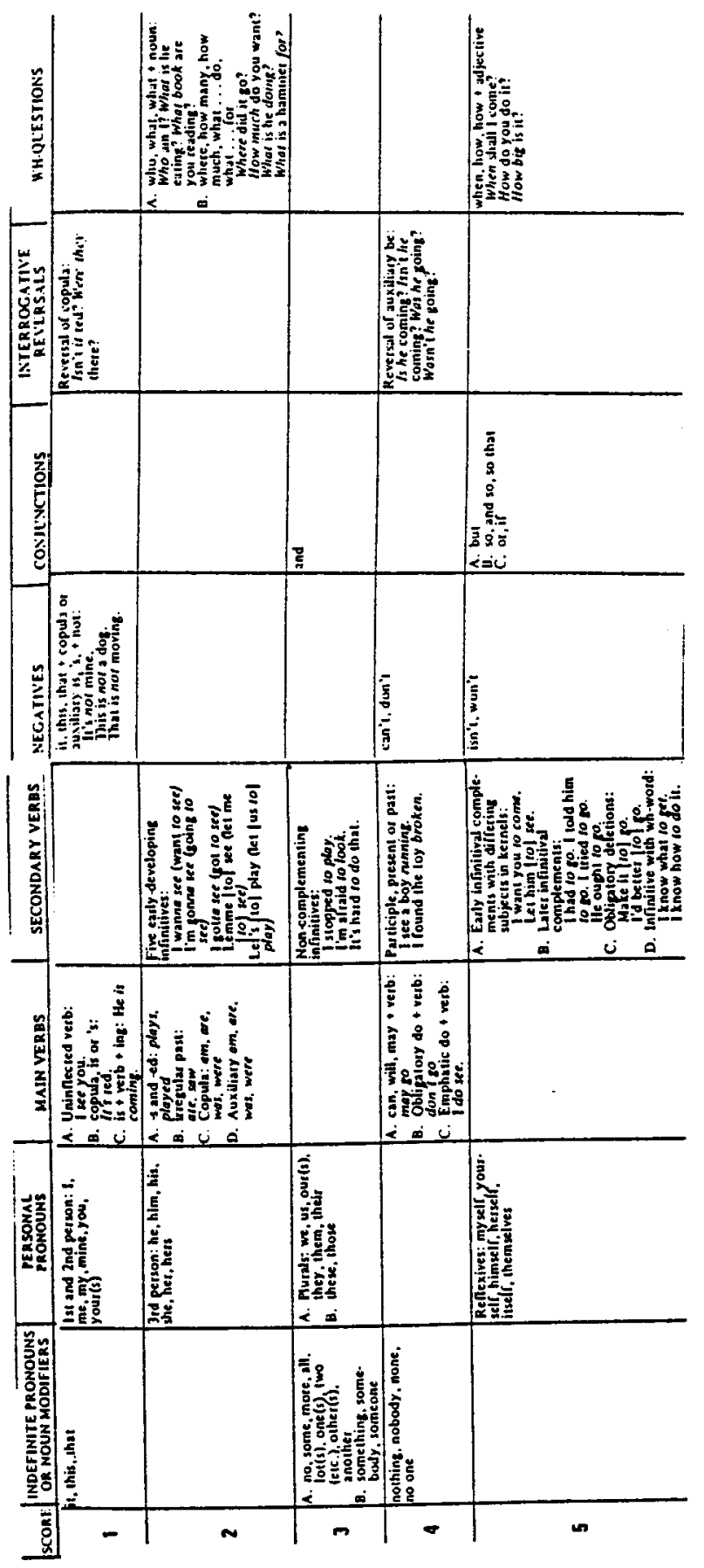




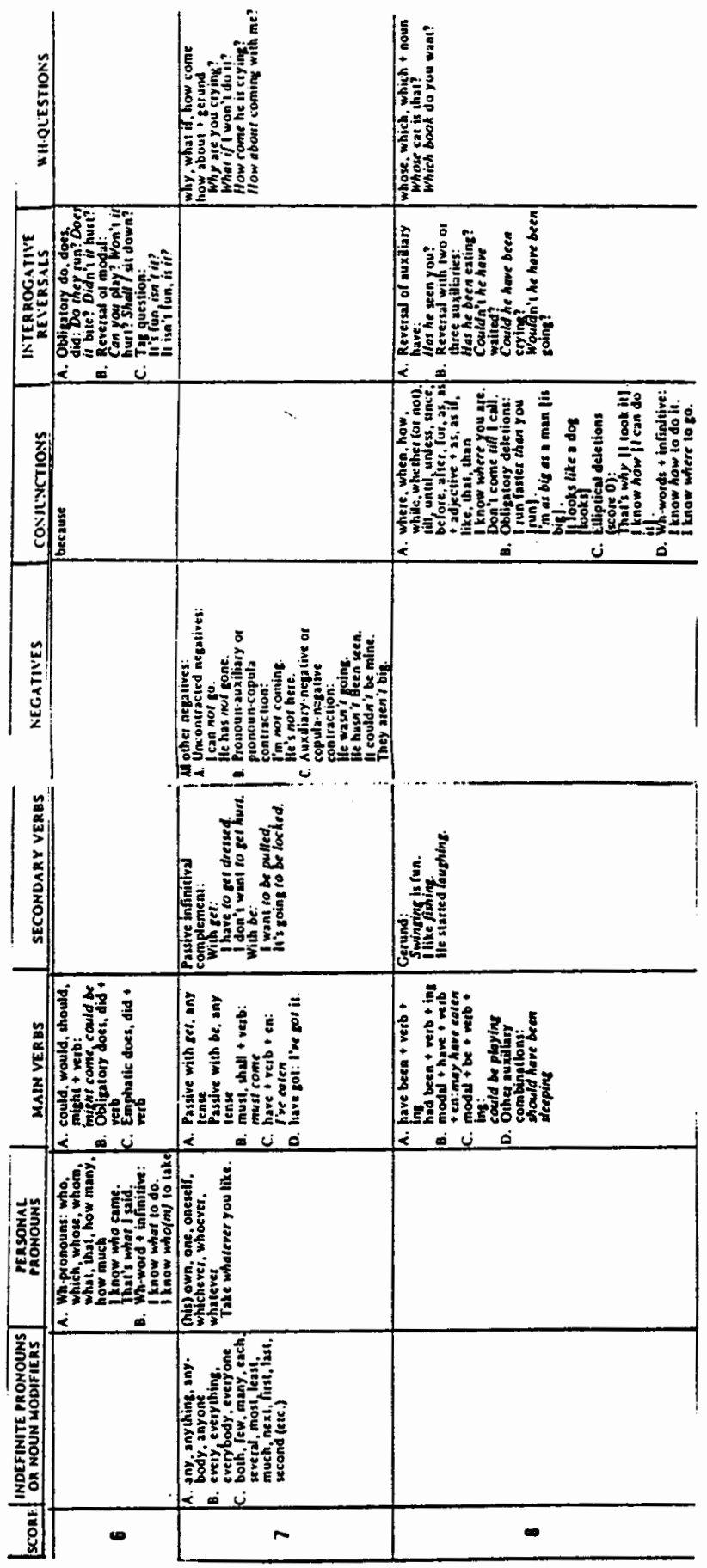




\section{APPENDIX B \\ DEVELOPMENTAL SETENCE SCORE: \\ NORMS}

Source: Lee, L. (1974). Developmental sentence

analysis. Evanston, IL: Northwestern University

Press. 
Figure 1. Norms for Developmental Sentence Scoring (Reweighred)

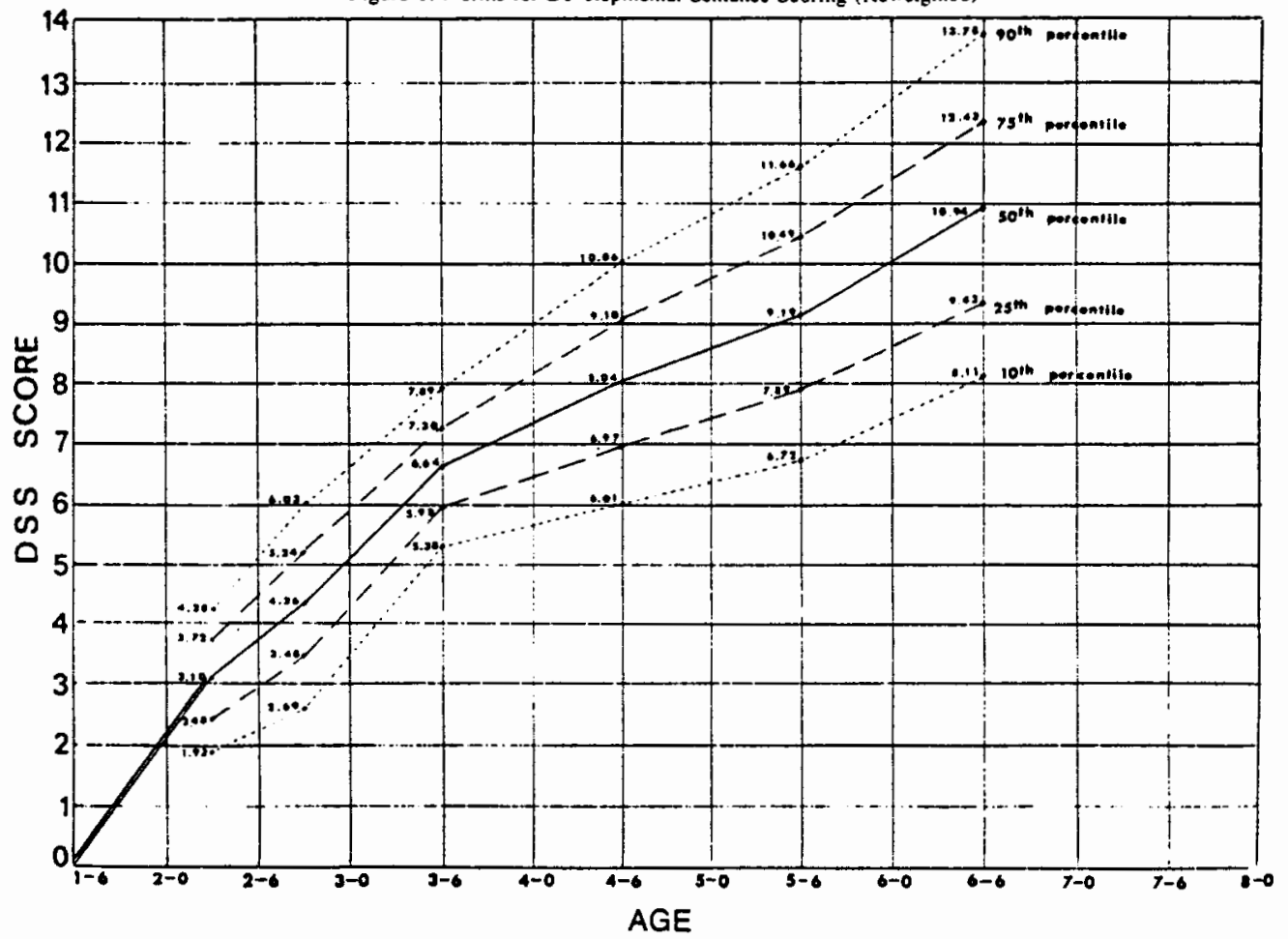


APPENDIX C

\section{OREGONIAN ARTICLE}




\section{Toddlers with delayed speech sought}

A Portland State University researcher is looking for otherwise normal toddlers who begin talking late to serve as subjects in a study of delayed speech and its connection, if any, to later language problems.

Rhea Paul, a PSU assistant professor of speech communication, said the reasons for delayed speech in "late-blooming" young children and the early identification of toddlers who later will suffer chronic language delay had not been well-investigated, although perhaps 10 percent of American children may fall into those categories.

Paul is interested in studying children between the ages of 18 and 30 months in the Portland-Vancouver area who can say only five or fewer words, instead of the 50 or so most children can speak by that age. She hopes to monitor their progress in speech development for two to five years, using such tools as speech tests and videotaped play sessions with their parents, to determine whether the children are indeed late-bloomers or whether their lack of early communication skills signals the start of severe speech and language delays.

Early identification of such children may allow early intervention and prevent future speech deficits, she said.

Paul's research is funded by the Fred Meyer Charitable Trust, the American Speech, Language and Hearing Foundation, and PSU. Parents who are interested in allowing their children to participate may contact Paul through the PSU Department of Speech.

The Oregonian, Portland, Oregon 
APPENDIX D

HUMAN SUBJECTS RESEARCH FORMS (D1 \& D2) 


\title{
HUMAN SUBJECTS RESEARCH \\ REVIEW COMMITTEE
}

\section{OFFICE OF GRANTS AND CONTRACTS}

\author{
DATE: $\quad$ May 24, 1991
}

TO. Rhea Paul, SP

FROM: Joan Shireman, Chair, HSRRC

RE. Your students' thesis/dissertation projects

With regard to your graduate students working with data from your research project entitled "Predicting Outcomes of Early Expressive Language Delay", application for Human Subjects Research Review may be unnecessary due to their procedures which involve the use of secondary data. However, if human subjects can be identified as data is handled, the Committee will need 10 review procedures for risk as there may be some in some studies.

If you have questions, please call me at $\times 5-5005$. Thank you.

c. Office of Grants and Contracts 


\title{
OFFICE OF GRADUATE STUDIES
}

\author{
DATE: $\quad$ May 18, 1992
}

TO:

FROM: Joan Shureghan, Char, HSRRC

RE: $\quad$ HSRRC Waived Review of Your Application entitled, "A Study of the Narrative Skills in Kindergarten Children with Normal, Impaired, and Late Developing Langugage Development"

Your proposal is exempt from further HSRRC review, and you may proceed with the study.

Even with the exemption above, it was necessary by University policy for you to notify this Committee of the proposed research and we appreciate your timely attention to this matter. If you make changes in your research protocol, the Committee must be notified.

c. Office of Graduate Sndies 
APPENDIX E

PARENT PERMISSION FORM 


\author{
COLLEGE OF \\ LIBERAL ARTS AND SCIENCES \\ DEPARTMENT OF \\ SPEECH COMMUNICATION \\ SPEECH AND \\ HEARINC SCIENCES
}

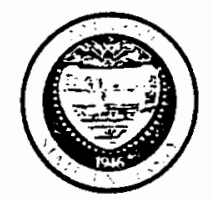

March 20,1987
PORTLAND
STATE
UNIVERSITY
P.O. BOX 751
PORTLAND. (IRFCION:
97207
$503.229 .35 \mathrm{J3}$

\section{Dear Parents,}

We are trying to learn more about the ways in which children develop an understanding of sentences, and compare the strategies normal children use with those used by children with disörders like mental retardation and autism. We would appreciate it greatly if you would allow your child to participate in our study, to be conducted at ECLC. Each child in the study will be taken from his/her classroom for 10-15 minutes and given a set of sentences to act out with toys (such as "Show me: the truck pushes the car.") Graduate students in speech-language pathology will conduct the testing under my supervision. Each child will receive a small gift for participating, and the school will receive a toy to thank the staff for their help. A brief summary of your child's performance on the task will be sent to you, for your information. Otherwise, all results will be kept strictly confidential.

Your cooperation in this study is completely voluntary and, if you decline to participate, the services your child receives at ECLC, Portland State University or anywhere else will not be affected in any way. If you choose to participate, you may withdraw at any time. While there will be no direct benefit to your child as a result of his/her participation, we think the results of the study will help us to understand better how normal children accomplish the task of learning language, and how children with disorders differ in their acquisition strategies.

If you would like to participate, piease sign the statement below and return this letter to me in the enclosed envelope. If you have any questions at all please do not hesitate to call me at 229-3533. Thank you for your cooperation.

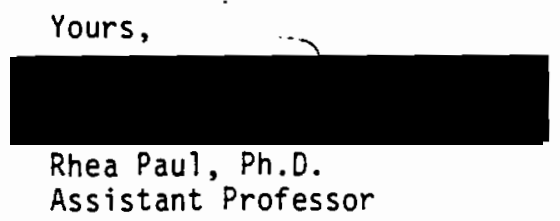

I give my permission for my child

whose preschool teacher is

to participate in the study described above.

Child's birthdate: 
APPENDIX F

QUESTIONNAIRE FOR PARENTS OF

CHILDREN 15-30 MONTHS OLD 
QUESTIONNAIRE FOR PARENTS OF CHILDREN 15-30 MONTHS OLD What is your child's:

first name?

date of birth?

Mother's (or primary parent's) full name?

Mother's (or primary parent's) phone number?

Mother's occupation

Father's occupation

How many different words can your child say? (It's oK if the words aren't entirely clear, as long as you can understand them).

none

less than five

$5-10$

$$
\begin{aligned}
& 10-30 \\
& 30-50
\end{aligned}
$$

more $\overline{\operatorname{than}} 50$

If your child says fewer than ten words, please 1 ist them here:

Does your child put words together to form short "sentences"?

Yes__ No

If yes, please give three examples here:

Would you be interested in participating in later parts of this study?

Yes

No 
APPENDIX G

LANGUAGE DEVELOPMENTAL SURVEY 


\section{APPENDIX \\ Language Developaient SuRver}

Dear Parent,

We are engaged in research on expressive language development in 2-yeat-old children. We are especially interested in learning unore about children who are slow in talking. We invite you to help us by completing this form and the vocabulary chectist on the back. Participation is entirely voluntary and all information given will be strictly confidential.

Thank vou.

Leslie Rescorla, Ph.D.

Date

- Your nanie

Child's name

Mother's name

Address.

Telephone

Date of birth

Marital status

Level of education completed.

Employment:

Not emploved

Employed part-time

Employed full-time

Occupation

Please give

age and sex of other children in fanily

Birthdate

․․․․

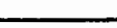

Has anvone in sour family been slow in leaming to talk?

If so, who?

Was your child premature?

How many weeks eariy?

How many ear infections has your child had?

Is child in daycare or cared for regularly by babysitter?

If so, how many hours per week?

What language is spoken in your home?

Please list languages spoken if other than English

Are you worried about your child's language development?

PLEASE COMPLETE VOCABULARY CHECKLIST ON THE REV'ERSE SIDE.

Please check of each word your child says. Don't include words your child cutn understand but not sas:. It's all right to count words that aren't pronounced clearly. Don't count words which your child repeats after you in intitation but does not say spontaneously.

\section{Father's naune \\ Address.}

Telephone

Date of birth

Marital status

Levei of education completed

\section{Emplovment:}

Not emploved

Employed purt-time

Employed full-time

Occupation 


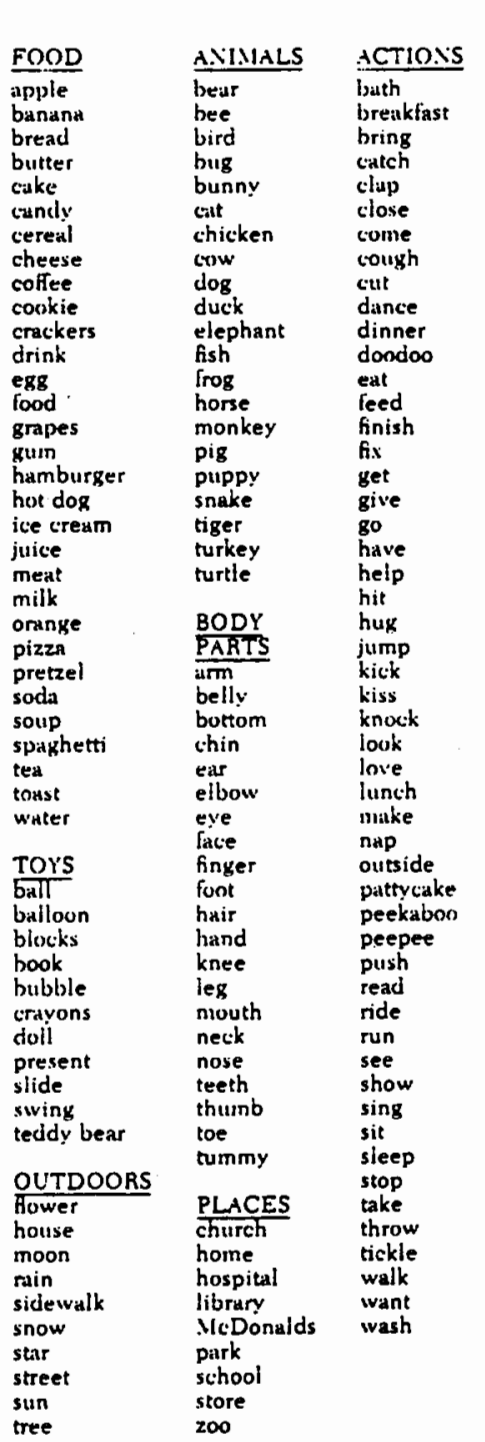

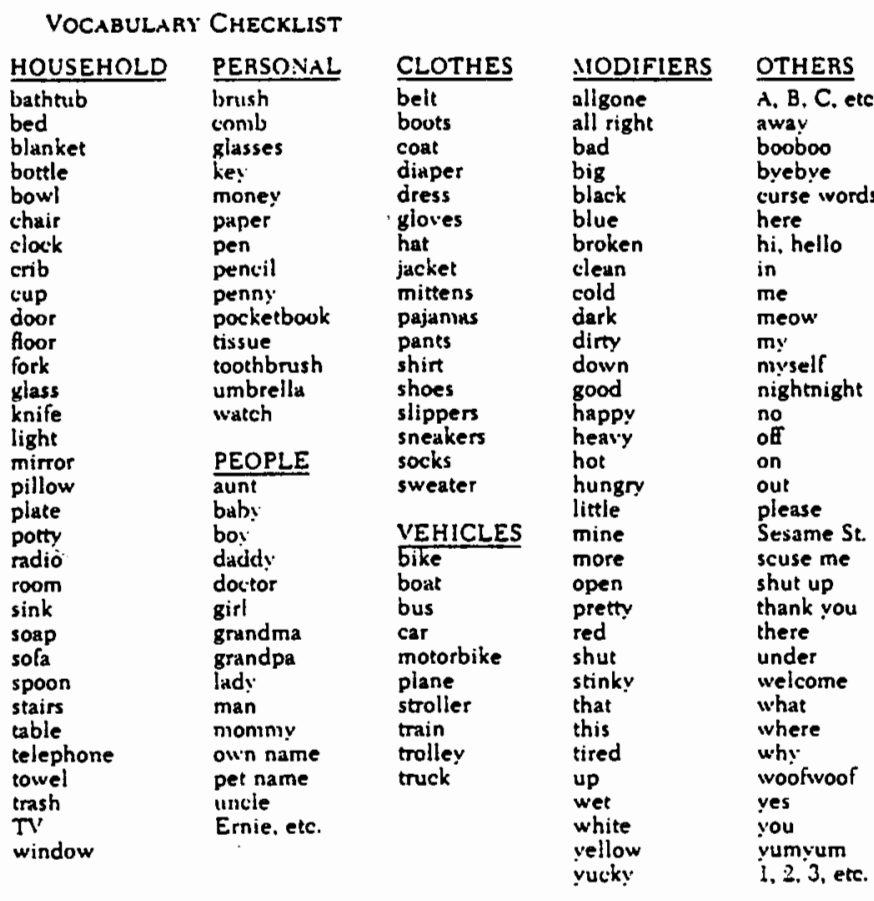

Please list any other words your child uses here:

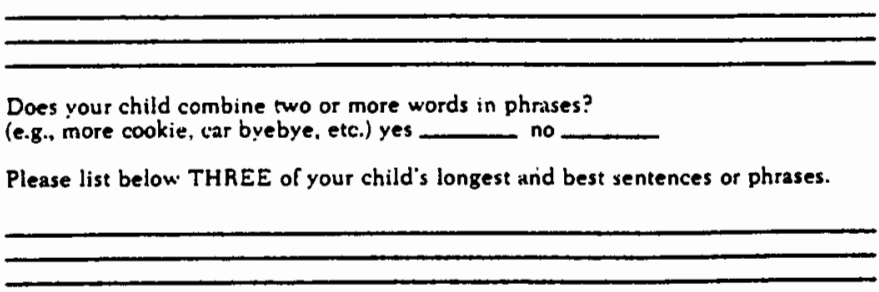

This survey instrument was developed by Leslie Rescorla, Ph.D. 


\section{APPENDIX H}

\section{RULES FOR COUNTING T-UNITS AND WORDS}

Source: strong, C. \& Shaver, J. (1991). Stability of cohesion in the spoken narratives of language-impaired and normally developing school-aged children. Journal of Speech and Hearing Research, 34, 95-111. 
RULES FOR COUNTING T-UNITS AND WORDS

The following rules were used for dividing the narratives into T-units and for counting the number of words in each $T-$ unit:

1. Exact repetitions of words or phrases were not counted.

2. Syntactic and/or semantic revisions that did not have a complete thought were not counted.

3. T-units were included even if not grammatically correct.

4. Direct quotations that completed a verb phrase were not considered as a separate $T$-unit.

5. Sentence fragments were counted when utterance final intonation contours clearly indicated that a complete thought had been spoken.

6. Unintelligible words or phrases were not counted. 


\section{APPENDIX I \\ 500 MOST COMMMON WORDS \\ USED BY 6 YEAR OLDS}

Source: Wepman, J. \& Hass, W. (1969) A spoken word count. Chicago: Language Resource Association. 
500 MOST COMMON WORDS USED BY 6 YEAR OLDS

\begin{tabular}{|c|c|c|c|}
\hline AND & HOUSE & TIME & VERY \\
\hline Is & MIGHT & THEIR & DARK \\
\hline THE & MOTHER & TREE & ANY \\
\hline $\mathrm{HE}$ & GIRL & PUT & ROCK \\
\hline A & WANT & KILL & HOW \\
\hline Tо & GOT & REAL & BED \\
\hline IT & LITTLE & WORK & MAKE \\
\hline SHE & KNOW & PICTURE & ONCE \\
\hline THERE & WENT & DOOR & SLEEP \\
\hline THEY & HAVE & SAID & FIND \\
\hline THAT & IF & BIG & HAND \\
\hline WAS & DOWN & MEN & LOT \\
\hline LOOK & HAS & TWO & SCHOOL \\
\hline IN & JUST & SIT & WATCH \\
\hline THIS & WITH & FROM & OLD \\
\hline NOT & BUT & CAUSE & RUN \\
\hline MAN & FOR & PEOPLE & SNOW \\
\hline GO & WHAT & NO & GOOD \\
\hline MAYBE & YOU & THESE & SAY \\
\hline THEN & DOES & INTO & HAIR \\
\hline WELL & WERE & HOME & Now \\
\hline I & WHEN & NIGHT & BLACK \\
\hline HER & SEE & ROOM & CLIMB \\
\hline LIKE & WILL & TELL & WALL \\
\hline so & BACK & HORSE & AFTER \\
\hline HIS & OTHER & WATER & HAPPEN \\
\hline OF & PLAY & GUY & TALK \\
\hline ON & CAME & WHERE & HOLD \\
\hline OR & ABOUT & BOOK & DIE \\
\hline ARE & FATHER & AROUND & MEAN \\
\hline ALL & THEM & TAKE & NOTHING \\
\hline $\mathrm{AT}$ & DAY & CRY & MARRY \\
\hline HIM & HAD & MORE & HAPPY \\
\hline SOME & COULD & OVER & READ \\
\hline LADY & WOULD & LIGHT & AGAIN \\
\hline THINK & COME & KISS & MAD \\
\hline ONE & PROBABLY & SAW & BEEN \\
\hline GET & DID & ANOTHER & FOUND \\
\hline DO & BOAT & OPEN & ELSE \\
\hline UP & TRY & SOMEBODY & BABY \\
\hline OUT & THING & RIGHT & FISH \\
\hline $\mathrm{BE}$ & HERE & TOO & WAY \\
\hline SOMETHING & WINDOW & END & LET \\
\hline BOY & LIVE & $\mathrm{OH}$ & KIND-OF \\
\hline BECAUSE & AWAY & BY & ASLEEP \\
\hline CAN & WALK & HARD & ANYTHING \\
\hline
\end{tabular}




\begin{tabular}{|c|c|c|c|}
\hline EVERYTHING & STATUE & BEFORE & BRING \\
\hline OFF & AM & LISTEN & STAR \\
\hline SOMEONE & PLANT & BRIDGE & PICK \\
\hline WHO & CALL & SHOT & RIDE \\
\hline SIDE & KID & HOT & BURY \\
\hline MADE & VIOLIN & TOGETHER & ANIMAL \\
\hline FALL & THROUGH & ALONG & STOP \\
\hline EAT & FRIEND & BROKE & NEW \\
\hline START & REALLY & FAST & WHATEVER \\
\hline WOMAN & EVER & EVEN & CABIN \\
\hline OUTSIDE & YEAR & STAIR & COAT \\
\hline LOVE & FIELD & LAMP & EXCEPT \\
\hline ME & RAN & JUMP & GONE \\
\hline AN & FIRE & LUNCH & SHOE \\
\hline NEXT & ASK & PAPER & SORT-OF \\
\hline WE & BEHIND & FOUR & BOX \\
\hline MONSTER & DOLL & KNIFE & OKAY \\
\hline ROPE & THOUGHT & STEP & YEAH \\
\hline SHOULD & NICE & HIMSELF & BUY \\
\hline MUCH & BETTER & BARN & PRAY \\
\hline HUSBAND & HEAD & MUST & WAR \\
\hline WAIT & SAD & US & CAVE \\
\hline WHITE & BRICK & MONEY & GAVE \\
\hline PLACE & GUESS & ALMOST & HOSPITAL \\
\hline FOOD & CHILD & CLOTHES & PAINTING \\
\hline TOOK & WONDER & ONLY & SHINE \\
\hline UPON & GIVE & FOREST & WEAR \\
\hline STORY & HURT & STUFF & GRANDMOTHER \\
\hline $\mathrm{EACH}$ & REST & MOUNTAIN & HILL \\
\hline GRASS & WOKE & LAY & INSTRUMENT \\
\hline KIND & HELP & FIVE & ARM \\
\hline DECIDE & FIX & SICK & PLOW \\
\hline ВОТН & EYE & DANCE & EVERY \\
\hline MY & STAND & TIRED & SHUT \\
\hline LONG & NEVER & NEAR & PART \\
\hline STAY & GROUND & GARDEN & DAUGHTER \\
\hline GUN & THREE & MOVE & FIRST \\
\hline BUG & GROW & YES & EVERYBODY \\
\hline CHILDREN & TOP & FEEL & INSIDE \\
\hline DEAD & UNTIL & HEARD & COAL \\
\hline WIFE & CAR & $\mathrm{DAD}$ & CORN \\
\hline SOMEWHERE & DOG & STONE & AS \\
\hline LEFT & FIGHT & READY & WOOD \\
\hline FELL & KEPT & TURTLE & BROKEN \\
\hline GRAVE & TABLE & LAKE & DONE \\
\hline TURN & HAPPILY & POLICE & GUITAR \\
\hline MORNING & KEEP & FACE & HIGH \\
\hline BAD & THOSE & TOLD & HARDLY \\
\hline FLOWER & WRONG & BLANK & PIECE \\
\hline PRETTY & STORE & OWN & GREAT \\
\hline UNDER & FARM & PAINT & PULL \\
\hline WHILE & SWIM & HAT & THOUSAND \\
\hline
\end{tabular}




\begin{tabular}{|c|c|c|}
\hline ITS & CARRY & YET \\
\hline FLOOR & HERSELF & WOLF \\
\hline WINTER & LINE & HAY \\
\hline COUNTRY & SNAKE & MOUSTACHE \\
\hline RIVER & STORM & \\
\hline DOCTOR & TORNADO & \\
\hline ATE & $\mathrm{BAG}$ & \\
\hline SISTER & COLD & \\
\hline BURN & WON & \\
\hline BROTHER & SEA & \\
\hline CHOP & TIE & \\
\hline SAIL & CARD & \\
\hline HOLE & FORGOT & \\
\hline ARMY & USE & \\
\hline CATCH & EVERYONE & \\
\hline SUMMER & YOUR & \\
\hline MOM & LEAF & \\
\hline WAKE & CUT & \\
\hline AGAINST & HUNDRED & \\
\hline CAUGHT & LOG & \\
\hline LAAND & MAY & \\
\hline ALREADY & ANT & \\
\hline $\mathrm{COUCH}$ & FINISH & \\
\hline CROSS & LESSON & \\
\hline EARLY & CASTLE & \\
\hline BEDROOM & CLEAN & \\
\hline BIRD & TUNE & \\
\hline NAME & CEMETERY & \\
\hline BURGLAR & DINOSAUR & \\
\hline GRANDFATHER & PRACTICE & \\
\hline BROUGHT & SOMEPLACE & \\
\hline ACROSS & CHAIR & \\
\hline CLOSE & STICK & \\
\hline RAIN & TEACH & \\
\hline SAME & FORGET & \\
\hline PAY & PET & \\
\hline CAT & SENT & \\
\hline GRANDMA & BOUGHT & \\
\hline SKY & CARE & \\
\hline WRECK & FUNNY & \\
\hline ANYBODY & TEN & \\
\hline DRY & SNOWY & \\
\hline ROBBER & STILL & \\
\hline KNOCK & SIX & \\
\hline SUN & SOON & \\
\hline COUPLE & BELOW & \\
\hline WHY & MINUTE & \\
\hline POND & $\mathrm{TV}$ & \\
\hline DEAR & GAME & \\
\hline $\mathrm{BIT}$ & SOMETIMES & \\
\hline SEED & BUMP & \\
\hline ALWAYS & FAINT & \\
\hline
\end{tabular}




\section{APPENDIX J}

\section{COHESION SCORING PROCEDURE}

Source: Liles, B. Z. (1985). Narrative ability in normal and language disordered children. Journal of Speech and Hearing Research, 28, 123-133. 
PROCEDURE FOR THE IDENTIFICATION

OF COHESIVE MARKERS

In this procedure it is important that the examiner be familiar with the original story being told. First read the entire narrative to get an overall sense of the text. Then read each sentence separately as a complete unit before identifying those items in the sentence that mark cohesion.

At this stage in the procedure the examiner views each sentence as isolated from the text. From this viewpoint the examiner judges an item to be a cohesive element or not under the following conditions.

1. Definition of a cohesive marker. An element is identified as a cohesive marker if its meaning cannot be adequately interpreted by the listener and if the listener must "search" outside that sentence for the completed meaning.

In addition, an element may be judged a cohesive element if it is used as a linguistic marker that leads the listener to "expect" that its interpretation is outside the sentence (e.g., definite articles).

Cohesive markers may be reference, conjunction, or lexical.

2. Relationships within the sentence. Do not judge an item as a cohesive marker if the information referred to is recoverable within the sentence. The following are examples of information recovered within the sentence.

Some boys took their car home.

Personal reference their refers to boys; therefore, the information is recoverable within the sentence.

There was this scientist that had a hideout in these mountains where there was this radar tower to blow up metal things that fly in the air.

In the example above the information referred to by the use of this and these as selective demonstrative references (Halliday \& Hasan, 1976 p. 70) is recovered within the sentence. Thus, the examiner would not identify this or these as a cohesive marker (i.e., information recoverable outside the sentence).

The next example demonstrates a cohesive and a noncohesive marker in the same sentence. 
One of the boys went home.

The demonstrative reference the marks which or what boys, and serves as a cue to the listener that the information is recoverable outside the sentence and is, therefore, cohesive. However, one refers within the sentence to boys and is not a cohesive marker.

3. Text influence on judgment. Although this procedure calls for the examiner to view each sentence as independent from the text when identifying cohesive markers, there are instances when the text must be considered. For example, in the sentence,

Marie didn't want to go on the hike.

the listener may need more information about Marie in order to comprehend the text. In this particular text, the listener would ask, "Who is Marie?"

Thus the decision as to whether a particular item is a cohesive marker or not is "text dependent." As texts vary specific items may vary in their cohesive function.

(a) Text influence on demonstrative reference. While the is a selective demonstrative reference, it may also be used in combination with words to express a unit of meaning (e.g., "the road," "the radio," "the newspaper"). It may be difficult to determine when the speaker intends the as a selective demonstrative reference or if the is used as an uninflected functor. To make this judgment, the examiner must take the text into consideration. For example, if the speaker used "the road" and the examiner judges that reference to a particular road is important within the text, he/she may judge that the speaker intended the to be used as a selective reference and would identify it as a cohesive marker. The following rule will facilitate judgment:

If in doubt about the use of because of the above reasons, do not code the as a selective demonstrative reference if $\underline{a}$ or some can be substituted without producing a crucial change in the meaning of the text.

4. Two or more cohesive markers within a sentence.

(a) conjunctions. When two or more conjunctions (e.g., and then or and so then) are conjoined in a sentence, code only one of the conjunctions as a cohesive item. select the the most complex according to the following 

hierarchy:
Temporal,
(a) Causal,
(2)
Adversitive,

(b) Reference: Demonstrative and comparative. When both a demonstrative and comparative reference are used (e.g., the other) code only as one cohesive item (comparative) rather than as two items (demonstrative and comparative).

(c) Reference: Personal and demonstrative. If two or more references (i.e., either personal or demonstrative) are judged to be cohesive in the same sentence, code all markers even though they refer to a common reference, for example:

He took his comic books home.

Although the sentence structure indicated that his refers within the sentence to he, there is no lexical support within the sentence to provide the listener with the information needed to know to whom his refers. Therefore, he and his are both cohesive.

After the examiner has identified the cohesive markers within each sentence according to the procedure presented above, he/she then reread the sentence with a different perspective. The markers that had been identified as cohesive are now viewed as part of the text.

Since each cohesive marker must (or should) be tied to the information recoverable elsewhere in the text, the examiner locates the sentence containing the tied information. The sentence number and item are noted.

\section{PROCEDURE FOR THE IDENTIFICATION OF COHESIVE ADEQUACY}

1. Complete tie. A tie is complete if the information referred to by the cohesive marker is easily found and defined with no ambiguity.

2. Noncomplete tie. A tie is judged to be noncomplete if: (a) the information referred to by the cohesive marker is not provided in the text, for example,

Two boys went to see a movie. They saw his car parked in front.

In this example, the speaker had not provided the information (i.e., whose car?) but used the personal reference his, cueing the listener to recover the information outside the sentence.

(b) the listener is guided to ambiguous information, for example, 
Homer and Freddie went to the movie. He enjoyed it very much.

In this case the listener would not know which boy enjoyed the movie.

Conjunctions are a special case of cohesive tying. All conjunctions that are not completely adequate are judged to be errors (or noncomplete). Accordingly, if the ideas or messages presented in the two conjoined sentences are unrelated or inappropriately sequenced, the conjunction used to join the ideas is judged to be noncomplete.

Further criteria for cohesion scoring (outlined by this investigator):

1. Sentences are total utterances, not T-units.

2. Use the information provided in false starts.

3. Do not count initial ands as conjunctions.

4. After doing worksheet, count up all the complete and noncomplete ties.

5. The raw score for each narrative is the total number of complete ties.

6. The frequency is the percentage of complete ties used in the narrative. Divide the number of complete ties by the number of noncomplete ties. 
Cohesion Worksheet:

Cohesive

Marker

line\#/item

complete/noncomplete
Tied to

info in

line\#/item
Marker

judgment

TOTAL COMPLETE

TOTAL NONCOMPLETE

$=$

$\%$ OF COMPLETE

TIES

+ TOTAL COMPLETE 
APPENDIX K

INFORMATION SCORE CRITERIA 
SCORING FOR INFORMATION

Read the whole narrative. Go back and read the narrative, giving one point for each idea forming an essential part of the story.

Score only those ideas listed below.

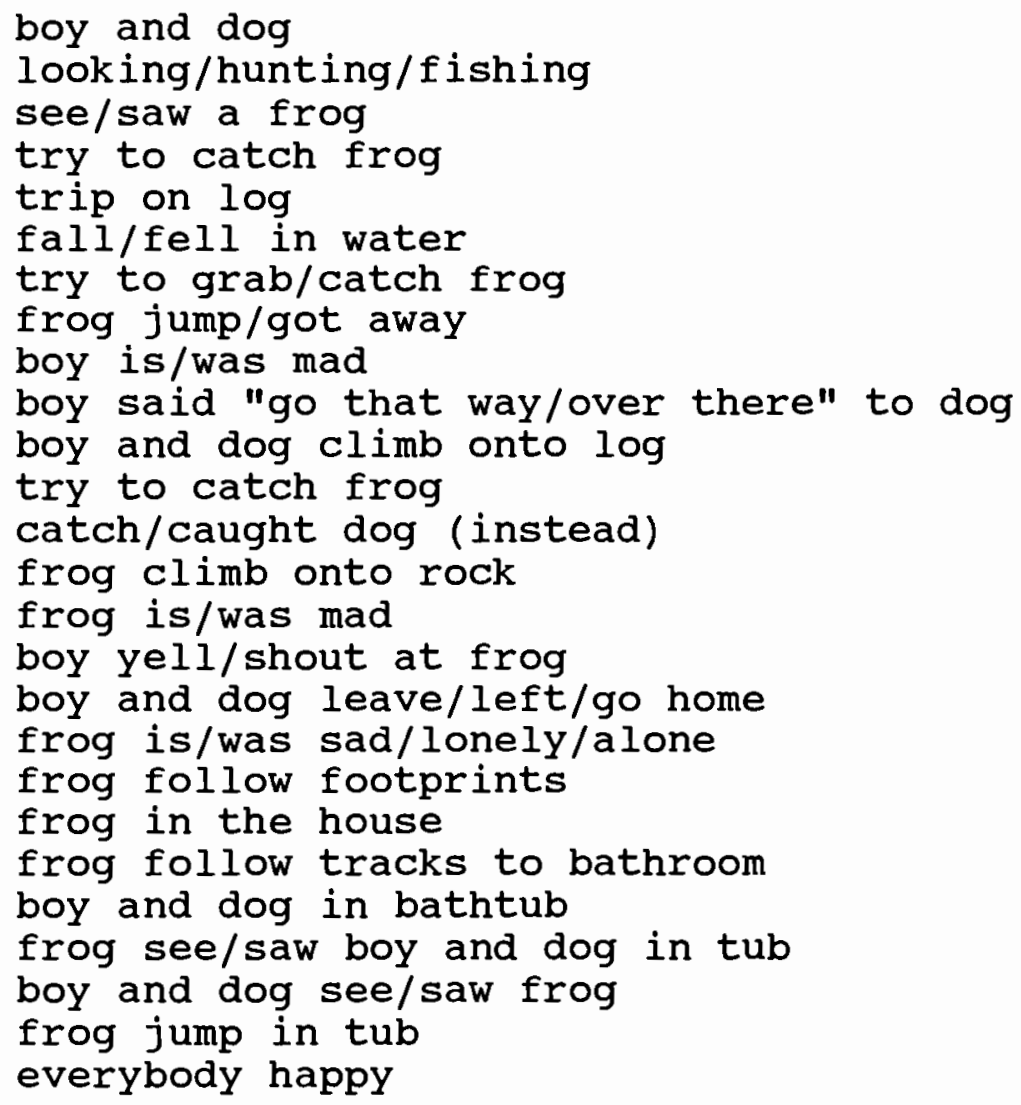

